Article

\title{
Development and Validation of a Thermo-Economic Model for Design Optimisation and Off-Design Performance Evaluation of a Pure Solar Microturbine
}

\author{
Davide Iaria ${ }^{1, *}$, Homam Nipkey ${ }^{2}{ }^{\mathbb{D}}$, Jafar Al Zaili ${ }^{1}$, Abdulnaser Ibrahim Sayma ${ }^{1}$ and \\ Mohsen Assadi 2 \\ 1 Department of Mechanical Engineering \& Aeronautics, School of Mathematics, Computer Science \& \\ Engineering, University of London, London EC1V 0HB, UK; Jafar.alzaili@city.ac.uk (J.A.Z.); \\ a.sayma@city.ac.uk (A.I.S.) \\ 2 Institutt for energi-og petroleumsteknologi, Stavanger University, 4036 Stavanger, Norway; \\ homam.nikpey@uis.no (H.N.); mohsen.assadi@uis.no (M.A.) \\ * Correspondence: iaria.davide@city.ac.uk; Tel.: +44-7576478587
}

Received: 11 October 2018; Accepted: 12 November 2018; Published: 18 November 2018

\begin{abstract}
The aim of this paper is to present a thermo-economic model of a microturbine for solar dish applications, which demonstrates the applicability and accuracy of the model for off-design performance evaluation and techno-economic optimisation purposes. The model is built using an object-oriented programming approach. Each component is represented using a class made of functions that perform a one-dimensional physical design, off-design performance analysis and the component cost evaluation. Compressor, recuperator, receiver and turbine models are presented and validated against experimental data available in literature, and each demonstrated good accuracy for a wide range of operating conditions. A $7-\mathrm{kW}_{\mathrm{e}}$ microturbine and solar irradiation data available for Rome between 2004 and 2005 were considered as a case study, and the thermo-economic analysis of the plant was performed to estimate the levelised cost of electricity based on the annual performance of the plant. The overall energy produced by the plant is 10,682 $\mathrm{kWh}$, the capital cost has been estimated to be EUR 27,051 and, consequently, the specific cost of the plant, defined as the ratio between the cost of components and output power in design condition, has been estimated to be around EUR 3980/ $\mathrm{kW}_{\mathrm{e}}$. Results from the levelised cost of electricity (LCOE) analysis demonstrate a levelised cost of electricity of EUR 22.81/ kWh considering a plant lifetime of 25 years. The results of the present case study have been compared with the results from IPSEpro 7 where the same component characteristic maps and operational strategy were considered. This comparison was aimed to verify the component matching procedure adopted for the present model. A plant sizing optimisation was then performed to determine the plant size which minimises the levelised cost of electricity. The design space of the optimisation variable is limited to the values $0.07-0.16 \mathrm{~kg} / \mathrm{s}$. Results of the optimisation demonstrate a minimum LCOE of 21.5 [EUR/kWh] for a design point mass flow rate of about $0.11 \mathrm{~kg} / \mathrm{s}$. This corresponds to an overall cost of the plant of around EUR 32,600 , with a dish diameter of $9.4 \mathrm{~m}$ and an annual electricity production of 13,700 [kWh].
\end{abstract}

Keywords: solar dish; micro gas turbine; thermo-economic model; concentrated solar power

\section{Introduction}

The rapid growth of the world population, as well as the expansion of the industrial sector, has led to a continuously growing demand for electrical power. This growth, coupled with the need for reduction of greenhouse gas emissions, has created serious global challenges, e.g., achieving energy demand without violating increasingly stricter environmental regulations. This challenge has led to a 
considerable push to develop clean power generation technologies. In this context, there has been a renewed interest in concentrated solar power (CSP) development.

One of the available technologies in the market is dish CSP systems. These arrangements are composed of a reflective surface, which usually has the profile of a paraboloid. The paraboloid mirrors reflect incident sunrays to a solar receiver, redirecting the sunbeams to a small region at the focal spot. The receiver absorbs the irradiated energy and convert it as heat delivered to the plant's working fluid. A sun tracking system is usually adopted to follow the sun in all directions and maximise the annual capture of solar energy.

Parabolic dish systems boast the highest potential for solar conversion efficiencies of all the CSP technologies. The concentrator always presents its full aperture directly in the direction of the sun and avoids the optical efficiency drop due to the "cosine effect", which usually affects other arrangements [1]. Parabolic dish CSP can operate as a stand-alone system, generating heat and/or electricity even in zones with no connection to the grid, but can also be stacked to form larger power plants in a similar fashion to photovoltaic parks with almost half the land occupancy for the same electrical output.

Parabolic dish systems, typically powering a Sterling engine, are however the least commercially mature technology among all CSP plants. One of the main issues related to Stirling engine technology is leakage of the working fluid of the power cycle, which is usually pressurised helium or hydrogen, used due to their good heat-transfer characteristics. Since the molecular weights of these gases are low, engines are designed to operate at high pressure, from 5 to $20 \mathrm{MPa}$, to maximise the power output. Another problem of these power plants is their relatively short lifetime. To make the system economically feasible, a lifetime above 20 years is required, which is far above the lifetime of Stirling engines, usually characterised by a life cycle of 10-15 year [1]. It is therefore necessary to consider the replacement of components to increase the lifetime of the system.

An alternative to Stirling engines for solar dish applications is microturbines (MGTs). As shown by Figure 1, MGTs are usually characterised by an open recuperated-Brayton Joule cycle. Intake air is compressed before entering a recuperator where a partial heat recovery of the exhaust gas allows increased maximum cycle efficiency. Air is then heated in the solar receiver before expansion in the turbine. Small-scale microturbines for solar applications have been investigated as an alternative to the Stirling engine and the number of research activities aimed at improving this technology has increased significantly in recent years. Most of these have focused on the improvement of single critical components, such as the solar receiver [2,3], the solar concentrator [4] or the microturbine [5]. This development was boosted by large-scale projects, aiming to demonstrate technical solutions. The OMSoP (Optimised Microturbine Solar Power system) project [4] started in 2013 and investigated the feasibility of coupling microturbines with CSP technology. For this purpose, a test plant has been built using a 7-kW $\mathrm{kGT}$ and dish technology in the ENEA (Ente per le nuove tecnologie, l'energia e l'ambiente) site in Casaccia, Rome. The plant, with configuration shown in Figure 1, was used to acquire the necessary knowledge to optimise the technology for future markets and evaluate its lifecycle. Moreover, the project performed worldwide cost market analysis to identify suitable regions for deployment of such systems [6]. 


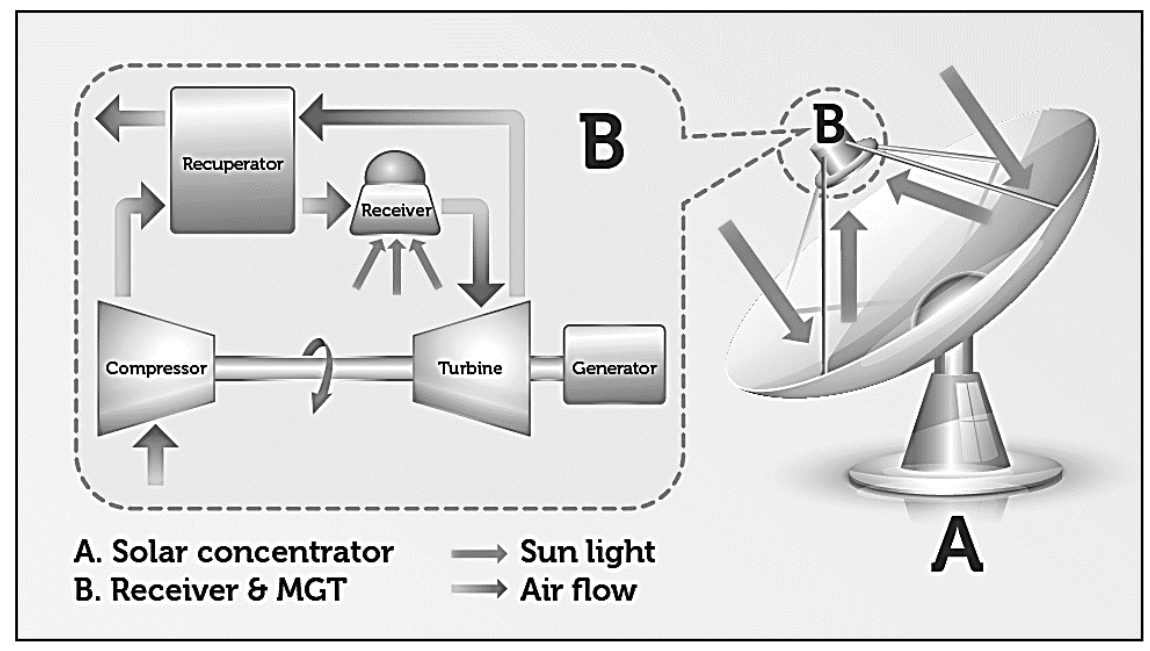

Figure 1. OMSoP solar based MGT system [4].

CSP systems are generally designed and analysed based on the nominal design point; given the intermittence of the solar radiation, they operate for most of the time in off-design conditions. Modelling plant performance is then an important aspect for detailed analysis and design and operation optimisation. The accuracy of the models and their applicability are key aspects to consider in software development. Mazzoni et al. [7] developed a simulation tool for a pure solar dish-micro gas turbine application tailored for the OMSoP project. The set-up of the CSP plant simulator is built on a modular arrangement at the component level as presented by Cerri [8]. A library of suitable component models for the plant was realised. The simulator has been adopted to perform steady state simulations for predicting the performance under variable direct normal irradiation. The biggest advantage of the modular approach is the prospect to generate any possible plant layout and integrate new components. This characteristic creates the possibility to include the desired number of compression and expansion stages and the option to integrate any number of heat exchangers for intercooled recuperative cycles. Moreover, modularity of the tool permits an easy integration of new components, such as a combustion chamber for hybrid operations and reheating cycles or thermal storage units.

On the other hand, for optimisation purposes it is important to evaluate different plant designs considering dissimilar main cycle design parameters. To evaluate the correct size of the plant is then necessary to design and evaluate off-design performances of a wide range of possible component assembly solutions. In this situation new components must be designed. In most of the commercial software available on the market for power plant analysis, the user is often provided with a library of components to choose from, resulting in less or limited flexibility, lower applicability in terms of component selection and poor adaptability to optimisation processes.

Gavagnin et al. [6] presented a paper aimed to find the optimum design and performance of a solar micro-turbine powered by dish collectors using an innovative methodology which integrates the design and off-design models of the system, tailored over existing components of the project OMSoP. This was in contrast to the common practice of assigning an estimated efficiency to the engine turbomachinery. The design model was run for two different sets of turbine inlet temperature and recuperator effectiveness (TIT and $\varepsilon$ ): $800{ }^{\circ} \mathrm{C}, 85 \%$ and $900{ }^{\circ} \mathrm{C}, 90 \%$. Different systems were designed for each case, yielding different off-design performance maps that link the net power output of the system to the boundary conditions of the site (ambient temperature and direct normal irradiation or DNI). With this information, annual simulations were performed in three different locations (Beijing, Seville and San Diego) based on standard performance maps for a reference DNI and on designs tailored to their particular DNI.

Ghavami [9] developed a computational model for pure solar dish-MGT systems. The model combines the cycle analysis of the MGT with component models to perform design point performance 
simulation, generate component performance maps and perform off-design performance evaluation. The computational model has been coupled with an up-to-date economic model which was specifically developed through the OMSoP project for dish-MGT systems.

The approach to dish technologies has been mostly technical in the past, although for a complete assessment of a solar dish MGT power plant an economic analysis is required. More recently, Semprini et al. [10] presented a thermo-economic evaluation of a dish-MGT solar power plant during hybrid and pure solar operation. The study included a comprehensive cost analysis covering manufacturing, transportation and installation for a dish and MGT solar power generator, considering pure solar and hybrid operations. The study demonstrated that for the pure solar system, the average system purchase equipment cost, considering a production volume of 1000 units/year, was EUR $3262 / \mathrm{kW}_{\mathrm{e}}$ for the solar-only configuration and EUR 3302/ $\mathrm{kW}_{\mathrm{e}}$ for the hybrid version. Regarding the dependence on MGT size, the minimum specific cost seems to be obtained for an air mass flow rate in the order of $200 \mathrm{~g} / \mathrm{s}$ even if further, more refined optimisation is still needed to find the true optimal combination of size, technical specifications, layouts and configuration.

Ghavami [6] also performed a thermo-economic optimisation of a pure solar MGT. The model already described in the previous paragraph was coupled to an optimisation tool to find system designs which led to optimal thermo-economic performance for a $5-\mathrm{kW}_{\mathrm{e}}$ system. Then, the optimisation was extended over the rated power of 5-30 kWe to find the power rating which results in the minimum cost of generated electricity by the dish-MGT systems. To generate new performance maps of the components the model adopted scaling techniques.

Despite years of development, solar micro turbines are still in an early stage of development and needs further technological progress in order to achieve competitiveness and to be ready for a global scale commercialisation. This is especially true for the MGT dish, for which development is still at a demonstration level and, in general, the following flaws have been identified in the cited previous works in the topic:

- Low aptitude for optimisation. Most existing tools and studies are based on existing plants, resulting in reduced capability of the tool to design and evaluate accurately off-design performance of different components.

- Scarce flexibility. Most existing tools do not allow the possibility to integrate new components and consequently compare dissimilar layouts.

- Few thermo-economic assessments and optimisations concerning solar dish-MGT, and none considering integrated hybridization (fuel back-up) and/or thermal storage.

In this paper, a validated model of a microturbine for solar dish applications is presented to be used for techno-economic optimisation purposes. The aim of this study is to create a flexible and modular tool for design and off-design performance evaluation, which can be adopted for different plant layouts and operational strategies. The developed tool is not intended to be used only for optimisation purposes but can also be adopted to evaluate the performance of existing plants and components. In the first part of the paper the logic of the tool, together with the components' models, are presented and validated. In the following results section the model is adopted for a thermo-economic assessment of a $7-\mathrm{kW}_{\mathrm{e}}$ power plant. Finally, a plant size optimisation is presented to find the optimum size of the plant in respect of the annual power output and the component's cost.

\section{Materials and Methods}

In this section, an overview of the model is presented. First, the logic approach of the software is introduced together with the components' model description and validation. An object-oriented programming approach was used to guarantee modularity of the components in the code and to enable the possibility to integrate new modules in the future, such as combustion chambers and thermal storage. Each module represents a plant's component, performing design and off-design calculations. A case study follows to demonstrate the capability of the software for performance prediction and cost 
evaluation. Finally, a plant-size optimisation is performed to evaluate the best size of the plant that can guarantee the right trade-off between plant cost and annual power generation.

To evaluate the performance of the plant in different operational conditions, a model for each component of the plant has been developed using a modular approach. The flowchart of the model is shown in Figure 2 where the generic Jth module is characterised by two functions. The first is the 'design function' which calculates the design performance and the geometrical characteristics of the component based on the desired set of design input variables. The second is the 'off-design function' which evaluates the performance of the plant at off-design conditions based on the geometrical characteristics. The latter is calculated by the design function, the required set of input variables at off-design conditions and the operational strategy, for instance constant TIT. The model has been programmed using the object-oriented language $\mathrm{C}++$.

The biggest advantage of the modular approach is the possibility to generate any desired plant layout. This characteristic allows the possibility of including the desired number of compression and expansion stages, the possibility to integrate any number of heat exchangers for intercooled recuperative cycles, or the possibility to integrate a combustion chamber for hybrid operations and reheating cycles.

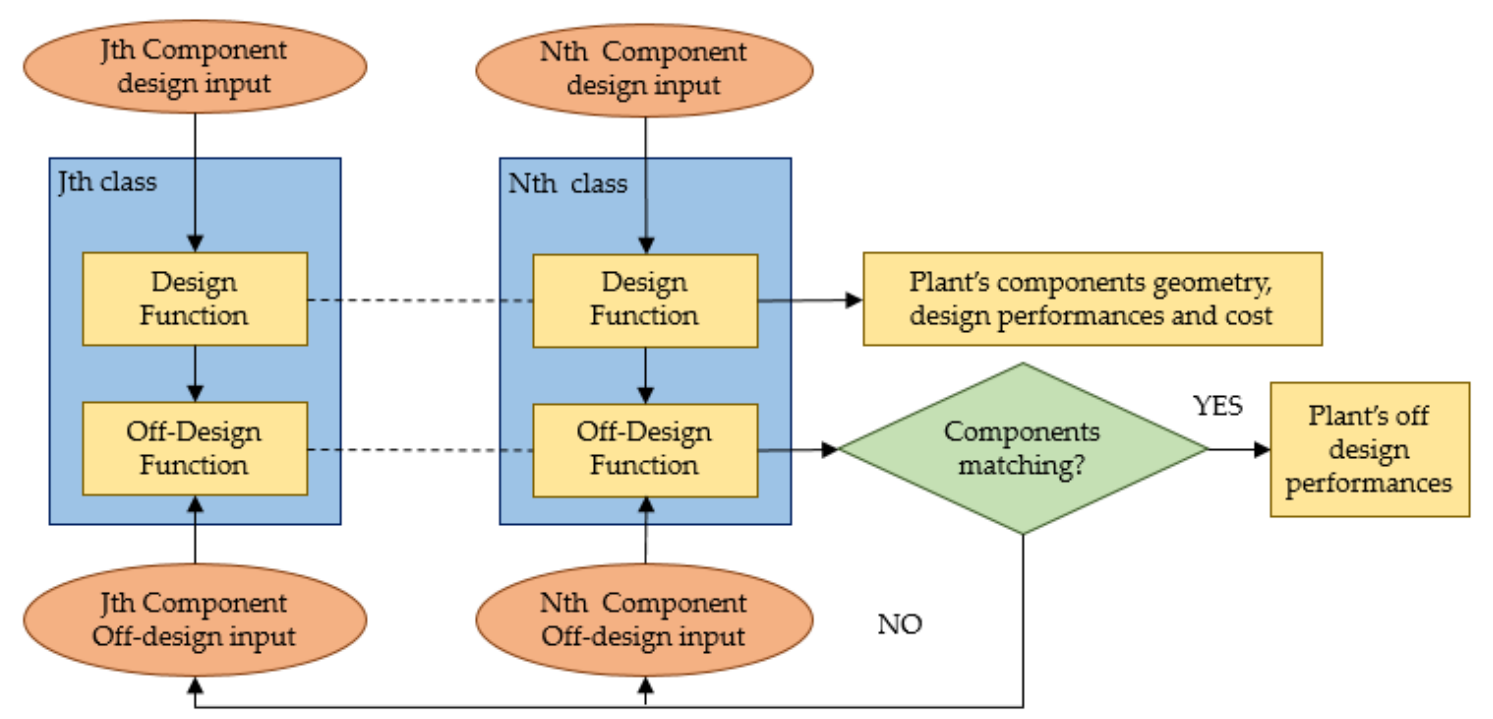

Figure 2. Logic flowchart of the code.

In this study, a recuperative cycle is presented. Once the components are selected, the first calculation carried out by the software is to design the plant and its main components using design point input parameters. After the design procedure is completed, the program evaluates the off-design performance of the components based on the desired operational strategy. The off-design procedure starts by assuming a first attempt mass flow rate and iterates until all the components match each other. During iteration the matching guess is continuously updated until component matching is achieved. Further constraints can be included in the software according to the operational strategy. In this case another iteration is required and the system is solved via serial nested loops. The loops matching guesses and constraints are solved in a nested sequence until convergence.

\subsection{Components Models}

\subsubsection{Fluid Properties Module}

The fluid properties are characterised using a specific class, which can be accessed by any components' classes. Through this module, each working fluid can be described as an object with its 
composition and thermodynamic properties. The specific heat of the working fluid $C_{P}$ as a function of temperature $T$ is evaluated using the first order polynomial regression given in Equation (1).

$$
C_{P}=\sum_{k=1}^{N} \mu_{k}\left(A_{k}+B_{k} T\right)
$$

where $A$ and $B$ are two coefficients characteristic of the single component $k$ and $\mu$ is the mass fraction of the component $k . N$ is the total number of the constituents of the fluid. To evaluate thermal conductivity and viscosity, for the purpose of this study, the class was calibrated to consider dry air as the working fluid, using a second order interpolation of the known properties of air as a function of the temperature [11]. The effect of pressure is negligible and hence was not considered.

\subsubsection{Microturbine}

The MGT is modelled by its three main components: the compressor, the recuperator and the turbine. Typically, for MGT applications, centrifugal compressors are adopted. This is mainly due to their robustness for the range of mass flow rates and pressures in which MGTs operate. Additionally, a previous study conducted by the authors demonstrated that an optimised design that utilises a vaneless diffuser can lead to a wider range of operation with relatively high efficiency compared to vaned diffuser designs [12]. Hence, a centrifugal compressor design with stationary casing, impeller, stationary vaneless diffuser and volute has been adopted for this study. The design and off-design performance evaluation have been performed using a one-dimensional model based on mass, momentum and energy conservation principles as given in Equations (2) and (3).

$$
\begin{gathered}
\dot{m}=\rho_{\text {in }} \pi\left(R_{\text {in }, t}^{2}-R_{\text {in }, h}^{2}\right) C_{a, \text { in }}=2 \pi R_{\text {out }} b_{\text {out }} C_{a, \text { out }} \rho_{\text {out }} \\
T_{0, \text { out }}=T_{0, \text { in }}\left(\frac{p_{0, \text { out }}}{p_{0, \text { in }}}\right)^{\frac{\gamma-1}{\gamma} * \frac{1}{\eta p c}}
\end{gathered}
$$

In Equation (2), $R$ is the radius, $b$ is the blade width, $\rho$ is the density and $C_{a}$ is the axial component of the absolute velocity. The subscripts $t$ and $h$ refer to the inlet hub and tip. In Equation (3), $T_{0}$ and $p_{0}$ are the total temperature and pressure, $\eta_{p c}$ is the polytrophic compressor efficiency and $\gamma$ the specific heats ratio. In both equations, the suffixes in and out refer to the inlet and outlet, respectively.

The efficiency of the compressor was evaluated using a set of standard empirical relationships available in [13]. In the adopted loss model, two categories of losses have been modeled: external (parasitic) losses and internal losses. Internal losses include all the losses that cause a pressure drop across the main channel, such as incidence losses $\left(\Delta h_{i}\right)$, blade loading $\left(\Delta h_{b l}\right)$, skin friction $\left(\Delta h_{s f}\right)$, mixing losses $\left(\Delta h_{m l}\right)$, tip clearance losses $\left(\Delta h_{c l}\right)$ and vaneless diffuser losses $\left(\Delta h_{c d}\right)$. The external losses are all those losses characterised by an enthalpy loss but not a pressure loss across the main channel. The disk friction losses $\left(\Delta h_{d f}\right)$, the leakage losses $\left(\Delta h_{l k}\right)$ and the recirculation losses $\left(\Delta h_{r c}\right)$ belong to this category. The isentropic compressor efficiency then can be calculated using Equation (4), where $\Delta h_{s}$ is the isentropic compression enthalpy change.

$$
\eta=\frac{\Delta h_{s}-\Delta h_{i}-\Delta h_{s f}-\Delta h_{b l}-\Delta h_{c l}-\Delta h_{m l}-\Delta h_{v d}}{\Delta h_{s}+\Delta h_{r c}+\Delta h_{l k}+\Delta h_{d f}}
$$

The recuperator chosen for this study is a cross flow plate-fin heat exchanger with off-set strip fins. This arrangement has one of the highest heat transfer to volume ratios of all heat exchangers available in the market [11]. Design and off-design performances of the heat exchanger have been evaluated using the $\varepsilon-N T U$ method which provides a model for the effectiveness and the overall heat transfer coefficient as given in Equation (5).

$$
\varepsilon=1-e^{\left\{\frac{1}{\bar{\chi}} N T U^{0.22}\left[e^{-\chi N T U^{0.78}}-1\right]\right\}}
$$


where, $\varepsilon$ is the recuperator effectiveness, and $C_{\min }$ and $C_{\max }$ are the minimum and maximum heat capacity rates between the hot and cold fluids defined as the product of the mass flow rate and the heat capacity at constant pressure. NTU is the number of transfer units defined as $U A / C_{\min }$ and $\chi$ is the ratio between $C_{\min }$ and $C_{\max } . U$ and $A$ are the overall heat transfer coefficient and the total heat transfer rate, respectively. The heat transfer mode is mainly convective in the recuperator and the heat transfer coefficients $(h)$ are predicted using Chilton-Colburn J-factor analogy [11] as given in Equation (6) as a function of the Colburn number, $(J)$, which is a function of the Reynolds number and the geometry.

$$
h=\frac{J G C_{p}}{P r^{2 / 3}}
$$

where $G$ is the volumetric flow rate, $C_{p}$ is the specific heat at constant pressure and $P r$ is the Prandtl number. Pressure losses due to friction have been evaluated using the semi-empirical correlations proposed by Manglik et al. [14] which relates the Colburn number and the friction factor to the Reynolds number and the geometry of the channels of the heat exchanger.

The considered expander is a radial inflow turbine. Using the same approach adopted for the compressor, the design performance evaluation has been performed using a one-dimensional model based on conservation of mass, momentum and energy for the flow in the turbine.

$$
\begin{gathered}
\dot{m}=2 \pi R_{\text {in }} b_{\text {in }} C_{a, \text { in }} \rho_{\text {in }}=\rho_{\text {out }} \pi\left(R_{\text {out }, t}^{2}-R_{\text {out }, h}^{2}\right) C_{a, \text { out }} \\
T_{0, \text { out }}=T_{0, \text { in }} *\left(\frac{p_{0, \text { in }}}{p_{0, \text { out }}}\right)^{\frac{\gamma-1}{\gamma} * \eta_{p, t}}
\end{gathered}
$$

The efficiency of the turbine has been evaluated using a set of empirical relationships that can be found in the literature [15]. The losses considered in this model are: incidence loss, passage loss, skin friction, blade loading, mixing losses, losses due to secondary flows, tip clearance loss, windage loss, and scroll loss. Incidence loss is caused by the deviation of the in-flow angle from the blade optimum design angle. Passage loss includes all the losses occurring in the main impeller passage. Tip clearance loss is a consequence of leakage from the pressure to suction sides occurring at the tip of the blade and can be evaluated by modelling the leakage flow and considering a simplified geometry of the shroud with a clear separation between axial and radial components. Windage loss is caused by the flow leaked onto the back face of the turbine disk and nozzle and scroll loss is due to the skin friction occurring in the scroll. Considering all the losses discussed so far, it is possible to evaluate the turbine efficiency using Equation (9), where $\Delta h_{s}$ is the isentropic expansion enthalpy change.

$$
\eta_{s T S}=\frac{\Delta h_{s}-\sum \Delta h_{l o s s}}{\Delta h_{s}} .
$$

For off-design calculations, a relationship between the mass flow rate and pressure ratio is required. The mass flow rate can be expressed as a function of the outlet static pressure, rotational speed and inlet temperature. The relationship between these three parameters can be represented in a Cartesian coordinate system with the law of the ellipse or Stodola cone. This relationship has been widely applied for steam turbines and is acceptably accurate for a high number of stages, but is not particularly suitable for radial in-flow turbine application. Moreover, this method does not consider the dependency on the rotational speed [16]. For the purpose of this study, the model was modified in order to take into account the dependency on the rotational speed and the turbine polytrophic efficiency.

$$
\mu^{o f f}=\mu * \vartheta * \sqrt{\frac{\left(\frac{p_{\text {out }}^{\text {off }}}{p_{\text {off }}^{\text {off }}}\right)^{\frac{m-1}{m}}-1}{\left(\frac{p_{\text {out }}}{p_{\text {oin }}}\right)^{\frac{m-1}{m}}-1}}
$$


where $\vartheta$ is a function of the rotational speed, $\mu$ is the corrected mass flow, $m$ is the expansion polytrophic exponent of the thermodynamic transformation and $\vartheta$ is defined as:

$$
\vartheta=\sqrt{1.4-0.4\left(\frac{n^{o f f}}{n}\right)}
$$

\subsubsection{Receiver and Dish}

The receiver considered for the purpose of this study is a cylindrical air tube cavity receiver (Qiu, 2015). As shown in Figure 3, the receiver is composed of a cylindrical cavity surrounded by insulation. At the bottom of the cavity an optical splitter is used to ensure effective distribution of the solar beam over the inner surface of the receiver and, at the top of the cavity, a quartz glass is presented to minimise the convective heat loss between the receiver and the ambient. The performance of an air tube cavity receiver is strongly influenced by the losses due to natural convection and re-radiation to the surroundings [17] with predominant natural convection losses. The losses caused by the wind forced convection are negligible compared to the natural convection losses. The losses, and thus the efficiency of the receiver can be evaluated using Equations (12)-(15).

$$
Q_{\text {conv }}=h_{\text {conv }} A\left(T_{\text {wall }}-T_{\text {amb }}\right) .
$$

where the adduction heat transfer coefficient $h_{c o n v}$ is calculated though the Nusselt number described by Equation (13).

$$
N u_{\text {conv }}=0.88 \mathrm{Gr}\left(\frac{T_{w}}{T_{a m b}}\right) \cos \left(\theta_{i}\right)^{2.47}
$$

where, $G_{r}$ is the Grashoff number, $T_{w}$ is the wall temperature, $T_{a m b}$ is the ambient temperature and $\theta_{i}$ is the inclination angle of the receiver to the vertical direction. Properties of the fluid are calculated at the film temperature, the arithmetic average between the ambient and the wall temperature. The other contribution to losses is due to irradiation phenomena and can be decomposed into two components: the re-irradiation, which is the characteristic of high temperature materials (Equation (14)) and the radiation absorbed by the glass and reflected by the pipe surface (Equation (15)).

$$
\begin{gathered}
Q_{\text {rad } 1}=A_{c a v} \varepsilon_{p} \sigma_{b}\left(T_{w}^{4}-T_{a m b}^{4}\right) \\
Q_{\text {rad } 2}=\left(1-\alpha_{p}\right) Q_{s u n}+\alpha_{g} Q_{s u n}
\end{gathered}
$$

where $\varepsilon_{p}$ is the pipe emissivity, $\sigma_{b}$ is the Stefan-Boltzmann constant, $\alpha_{p}$ and $\alpha_{g}$ are the pipe material and the glass absorptivity, respectively. $Q_{\text {sun }}$ is the heat provided by the sun for the given dish diameter and dish optical efficiency. The absorbed heat by the receiver is passed to air, assuming perfect insulation, as given by (Equation (16)).

$$
Q_{a b s}=D N I * A_{d i s h} * \eta_{d i s h}-Q_{c o n v}-Q_{r a d 1}-Q_{r a d 2}=\dot{m} C_{p}\left(T_{i n}-T_{o u t}\right)=h_{p} A_{p} \Delta T_{M L} .
$$

where:

$$
\Delta T_{M L}=\frac{\left(\left(T_{w}-T_{\text {in }}\right)-\left(T_{w}-T_{\text {out }}\right)\right)}{\log \left(\frac{T_{w}-T_{\text {in }}}{T_{w w}-T_{\text {out }}}\right)}
$$

In the previous equations DNIis the direct normal irradiation provided by the sun expressed in $\left[\mathrm{W} / \mathrm{m}^{2}\right], A_{\text {dish }}$ is the dish area and $\eta_{\text {dish }}$ is the dish optical efficiency. In these equations, $h_{p}$ and $A_{p}$ are the pipe heat transfer coefficient and area respectively, $T_{i n}$ and $T_{\text {out }}$ are the air inlet and outlet temperature. The dish optical efficiency characterises the capacity of the dish to concentrate the incident sunrays at the receiver focal spot. The main factors reducing efficiency are the surface finishing of the 
mirror and the deviation of the dish surface from parabolic shape which causes the beam to spread over a wider area than the receiver window.

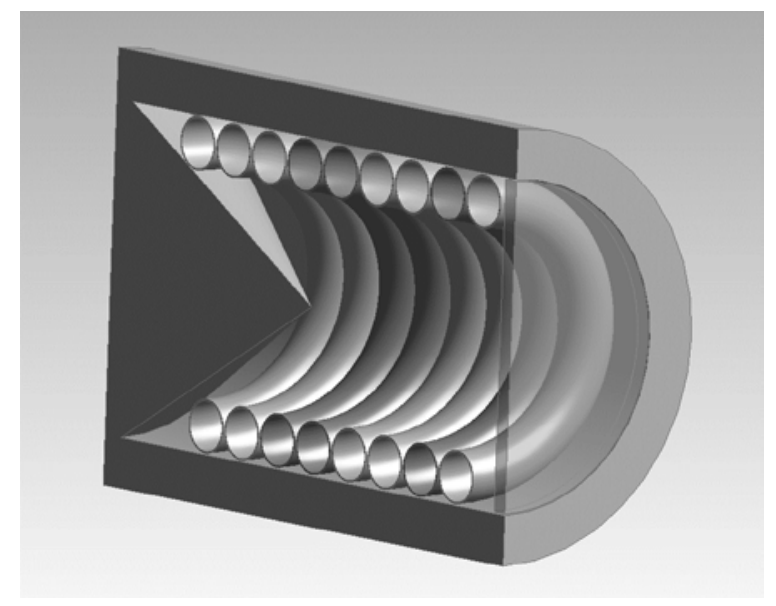

Figure 3. Breakthrough of the adopted cavity receiver.

The heat transfer and the pressure losses within the receiver pipe are evaluated considering a helically coiled tube. Many validated correlations to describe the heat transfer characteristics of a helicoidally coiled pipe are available in the literature. The model adopted in this study is the one proposed by Xin and Ebadian [18].

\subsection{Cost Analysis}

A detailed techno-economic analysis was carried out to evaluate the cost and the levelised cost of electricity of the plant in different arrangements. The analysis is based on the components' models and a series of cost functions to evaluate individual cost of each components, and other elements of cost of the system such as installation and maintenance.

Unlike large-scale gas turbines, only a few cost evaluation studies are available in literature for microturbines. For this study, the approach used by Galanti [19] has been used and the cost functions for the different components are described by the following equations where all the costs are given in euros.

$$
\begin{gathered}
C_{\text {compr. }}=55.8 * \ln \left(P R_{c}\right) *\left(\frac{\dot{m}}{0.942-\eta_{p c}}\right) \\
C_{\text {turb. }}=376.1 * \ln \left(P R_{t}\right) *\left(\frac{\dot{m}}{0.903-\eta_{p t}}\right) \\
C_{\text {recup. }}=9 f_{m}\left(625.1 \dot{m}\left(\frac{p_{\text {in }} \Delta p}{100}\right)^{-0.5} *\left(\frac{\varepsilon}{1-\varepsilon}\right)\right) \\
C_{\text {gen. }}=18.7 P^{0.95}
\end{gathered}
$$

where $P R_{c}$ and $P R_{t}$ are the compressor and turbine pressure ratios, $p_{i n}$ is the inlet pressure expressed in bar, $\Delta p$ is the recuperator percentage pressure loss, $\dot{m}$ is the mass flow rate in $\mathrm{kg} / \mathrm{s}, \varepsilon$ is the recuperator effectiveness and $P$ is the net power output in $\mathrm{kW}$. The cost of the generator also includes the cost of power electronics and has been evaluated using Equation (21). The receiver cost function was interpolated from a study conducted by Pioneer Engineering [20] for a pressurised air solar receiver, adaptable for a solar dish and microturbine system. The study considered direct labour costs, direct material costs and manufacturing costs. Results from this study were interpolated and Equation (22) was obtained which expresses the cost of the receiver as a function of absorbed heat.

$$
C_{R e c}=0.0304 * Q_{R e c} .
$$


In this equation, $Q_{\operatorname{Rec}}$ is the receiver input heat expressed in watts. The dish cost by far has the biggest contribution to the plant cost [7] and it needs careful consideration for adequate prediction of the cost. In this study, the dish cost was evaluated using a regression model as described by Equation (23) based on a study conducted by [21]. The study evaluated the specific prices of collectors in the range from $67 \mathrm{~m}^{2}$ to $230 \mathrm{~m}^{2}$ for different production volumes. According to [7] the exponent $n_{\text {Dish }}$ does not vary significantly from unity for a wide range of dish diameters, and, for this reason, a linear dependency of the dish cost on the area was considered.

$$
C_{\text {Dish }}=260 * A_{\text {Dish }}^{n_{\text {dish }}}
$$

where $A_{\text {Dish }}$ is the dish surface area in $\left[\mathrm{m}^{2}\right]$. The overall cost can be then calculated using Equation (24).

$$
C_{\mathrm{TOT}}=C_{\mathrm{MGT}}+C_{\text {Rec }}+C_{\text {Dish }}+C_{\text {inst }}
$$

In the previous equation, $C_{\text {inst }}$ is the installation cost, which includes the cost of installation and other costs not related directly to components. On the base of the findings of a study conducted by Gavagnin et al. [7], this has been approximated as $17 \%$ of the total components' costs. Using the Chemical Engineering Plant Cost Index (CEPCI) each calculated cost was discounted to update the costs at the current year as described in (Equation (25)).

$$
C_{\mathrm{j}}=\frac{C_{\text {ref }} *\left(\mathrm{CEPCI}_{\mathrm{j}}\right)}{\left(\mathrm{CEPCI}_{\mathrm{ref}}\right)}
$$

where $C_{j}$ is the cost at year $\mathrm{j}, \mathrm{CEPCI}_{\mathrm{j}}$ is the Chemical Engineering Plant Cost Index for year, $\mathrm{j}, C_{r e f}$ is a known cost of the components for a particular year and $\mathrm{CEPCI}_{\text {ref }}$ is taken for the same reference year. The levelised cost of electricity therefore can be calculated using Equation (26).

$$
\begin{gathered}
\mathrm{LCOE}=\frac{\alpha C_{\mathrm{TOT}}+C_{\mathrm{O} \& \mathrm{M}}}{E} \\
\alpha=\frac{i *(1+i)^{n}}{(1+i)^{n}-1}
\end{gathered}
$$

The capital recovery factor $\alpha$ has been evaluated considering typical values of $i=0.07$ for the actual interest rate and $n=25$ years for the lifetime of the plant. Operation and maintenance costs have been estimated to be $5 \%$ of the total cost as suggested by [22]. Costs of operation and maintenance has been considered as $5 \%$ of total costs, which includes capital and installation costs. Scale economy related to different production rates were not considered in this study.

\subsection{Model Validation}

In this section the model validation is presented. Given the lack of experimental data regarding solar dish-MGT power plant, the validation has been performed for each component. One or more validation case studies for similar designs to those investigated in this paper were considered for each component and results output from the present model have been compared with experimental data available in literature. Data about the models validation can be found in the supplementary materials provided by the authors.

\subsubsection{Compressor Off-Design Model Validation}

The compressor model has been validated against experimental data for three different compressor sizes [23]. Figure 4 shows the main geometrical characteristics of the impeller for these compressors. The results obtained from the model for the compressor efficiency and pressure ratio for different mass flow rates and rotational speeds are given in Figures 5-7. For the Eckardt impeller O, the validation demonstrates good accuracy for a wide range of operating conditions showing a maximum relative 
error of $2.5 \%$ for the efficiency and 3\% for the pressure ratio. Moreover, the curves demonstrate comparable behaviour and the error is located only in short sections of the curves. The same observations are valid for the Eckardt impeller A. In this case the model shows a maximum relative error of $4 \%$ for the efficiency and $4.3 \%$ for the pressure ratio. Despite the higher maximum relative error, the overall accuracy of the model is higher when compared with the Eckardt impeller A, especially regarding efficiency. On the other hand, the pressure ratio shows a more accentuated slope of the curve when getting close to the choking limit. Nevertheless, the accuracy of the model was considered acceptable for the purpose of this study.

For the case of KIMM compressor geometry, the efficiency chart was not available and the comparison has been performed only on the pressure ratio. Results show better agreement with the experimental results when compared to the other two compressor geometries showing a maximum relative error of $1.5 \%$. This demonstrates the suitability of the present model for smaller size compressors.

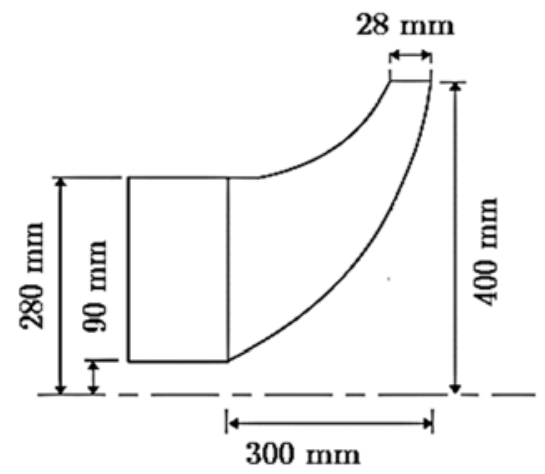

(a) Eckardt Impeller O

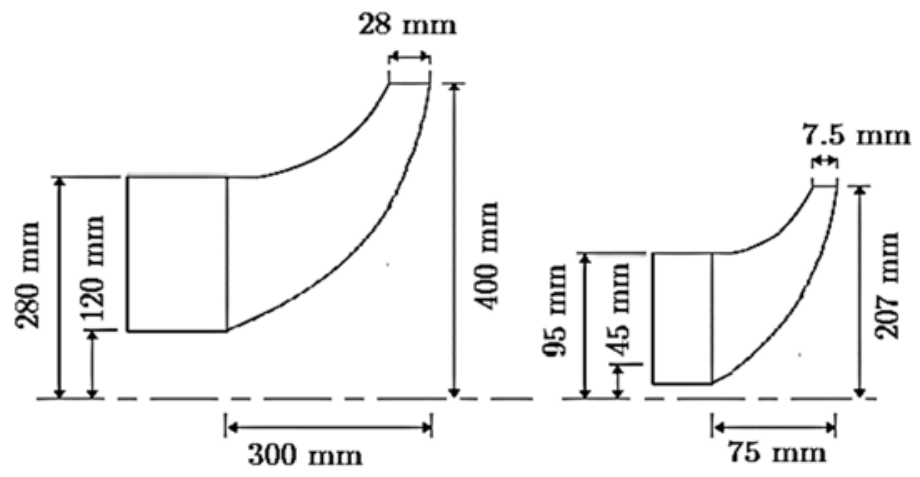

(b) Eckardt Impeller A

(c) KIMM Impeller

Figure 4. Impeller geometries considered for the validation (not in scale) [23]. (a) Eckardt impeller O. (b) Eckardt impeller A. (c) KIMM impeller.

$\begin{array}{llll}-10 \mathrm{krpm} 1 \mathrm{D} & -12 \mathrm{krpm} 1 \mathrm{D} & -14 \mathrm{krpm} 1 \mathrm{D} & -16 \mathrm{krpm} 1 \mathrm{D} \\ \cdots & 10 \mathrm{krpm} \text { Exp. } & \cdots & 12 \mathrm{krpm} \text { Exp. }\end{array}$

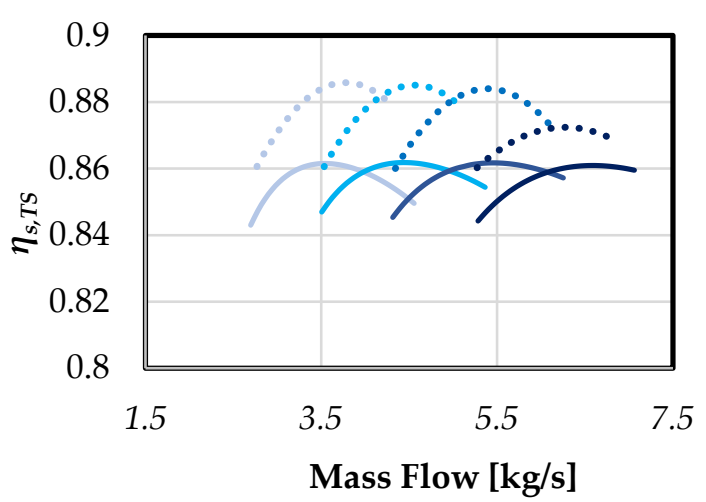

(a)

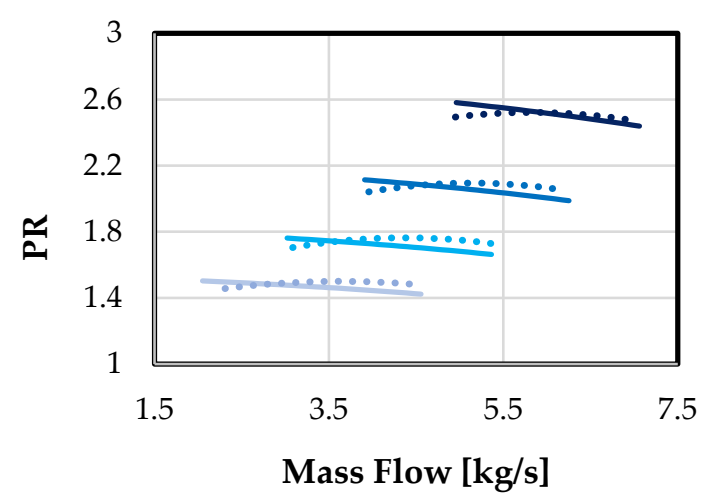

(b)

Figure 5. Compressor validation: characteristic maps for Eckardt impeller O. (a) Total to static isentropic efficiency vs mass flow rate; (b) pressure ratio vs mass flow rate. 
$10 \mathrm{krpm}$ Experimental $-10 \mathrm{krpm} 1 \mathrm{D}$

- $14 \mathrm{krpm}$ Experimental — $14 \mathrm{krpm} \mathrm{1D}$

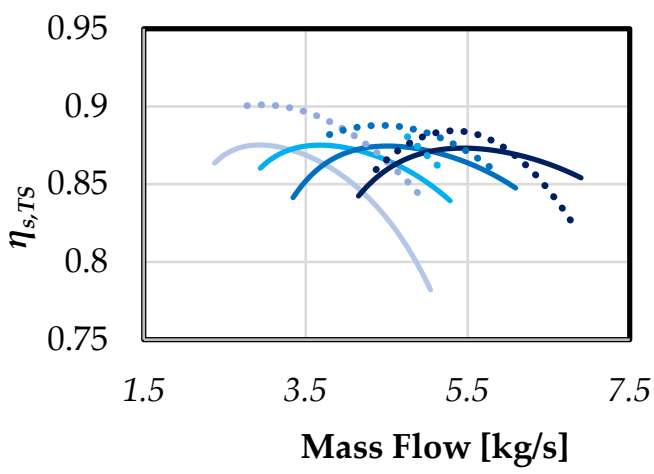

(a)
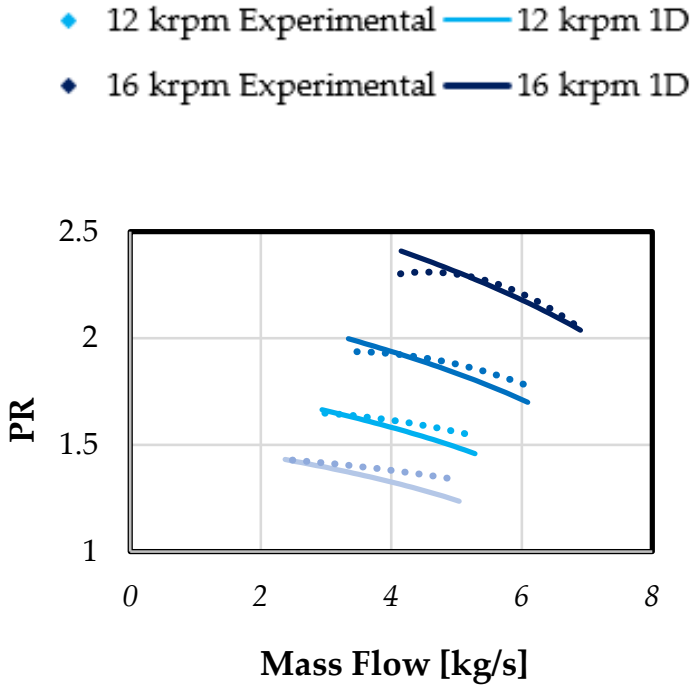

(b)

Figure 6. Compressor validation: characteristic maps for Eckardt impeller A. (a) Total to static isentropic efficiency vs mass flow rate; (b) pressure ratio vs mass flow rate.

$\begin{array}{llll} & 12 \mathrm{krpm} \text { Experimental } & -13.5 \mathrm{krpm} 1 \mathrm{D} & -13.5 \mathrm{krpm} 1 \mathrm{D} \\ -15 \mathrm{krpm} 1 \mathrm{D} & -15 \mathrm{krpm} \text { Experimental Experimental } & -15.75 \mathrm{krpm} \text { Experimental } & -15.75 \mathrm{krpm} 1 \mathrm{D}\end{array}$

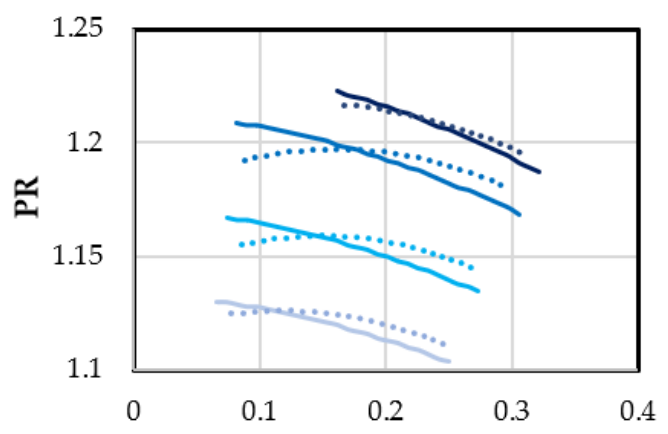

Mass Flow $[\mathrm{kg} / \mathrm{s}]$

Figure 7. Compressor validation: characteristic maps for KIMM impeller.

\subsubsection{Recuperator Off-Design Model Validation}

The model for the recuperator has been validated against available experimental data for a range of fin geometries as proposed by [24]. The fin geometries and arrangements used for the validation, namely, 1/10-27.03 and 1/8-16.00(D) fin geometries, are presented in Figure 8 and more details of the geometry are given in [24].

Figure 9 shows the modelling results of the Colburn factor (J) and friction factor (f) for both $1 / 10-27.03$ and 1/8-16.00(D) fin geometries. The modelling for the first geometry presents a maximum relative error of $3 \%$ for both Colburn factor and friction factor. Nevertheless, there is some inaccuracy in the results of the second fin geometry, with a maximum relative error around $18 \%$ for the Colburn number and $6 \%$ for the friction factor. Given the higher accuracy of the model in predicting the performance of the 1/10-27.03 fin geometry, this layout will be adopted by the model for the recuperator design. 


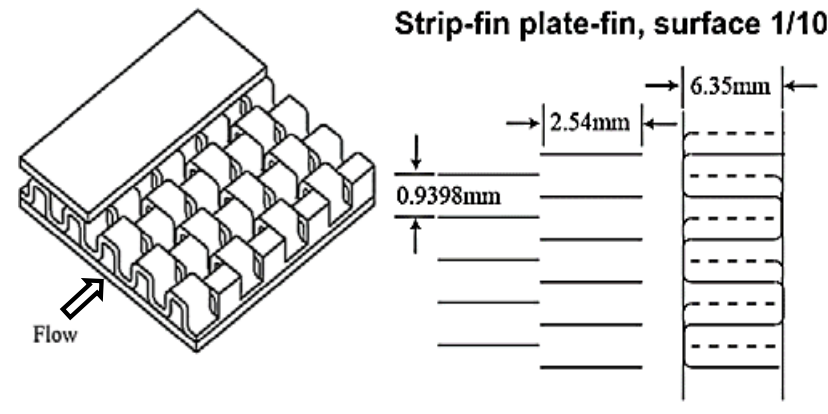

(a)
Strip-fin plate-fin, surface $1 / 8-16.00(D)$

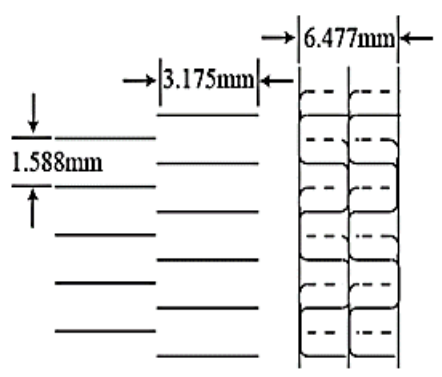

(b)

Figure 8. Fin geometries and arrangement considered for the recuperator model validation [24]. (a) $1 / 10-27.03$; (b) 1/8-16.00(D).

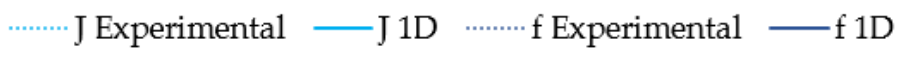

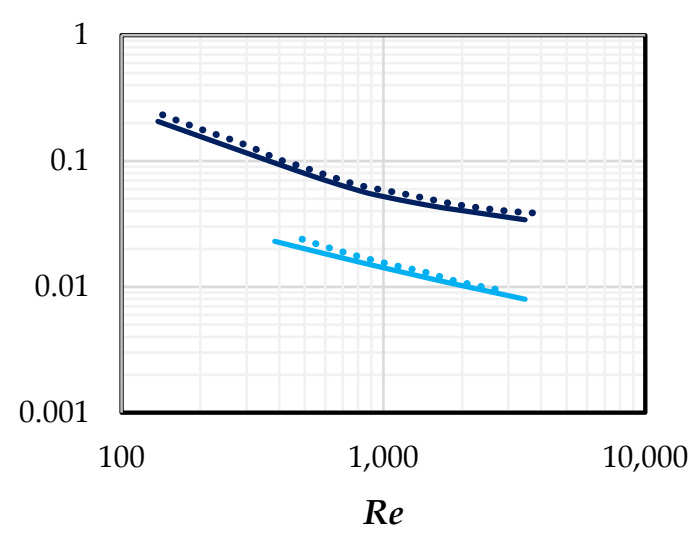

(a)

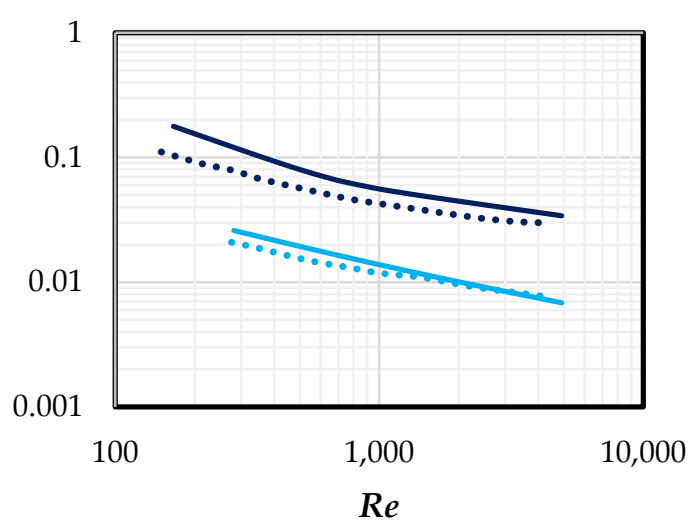

(b)

Figure 9. Comparison between experimental and analytical data. Colburn factor (cyan) and friction factor (blue). (a) Fin geometry 1/10-27.03. (b) Fin geometry 1/8-16.00(D).

\subsubsection{Receiver off-Design Model Validation}

The receiver model was validated by comparing the results obtained from the one-dimensional model with experimental results available in literature [25]. The receiver consists of 15-turn helically coiled copper tube with inner diameter of $12 \mathrm{~mm}$ and thickness of $1 \mathrm{~mm}$. The inner diameter and height of the cavity are $140 \mathrm{~mm}$ and $200 \mathrm{~mm}$, respectively.

Results shown in Figure 10 demonstrate good agreement concerning outlet temperature for a wide range of operating points with a maximum relative error below $2.5 \%$, which is considered adequate for the purpose of this study. 


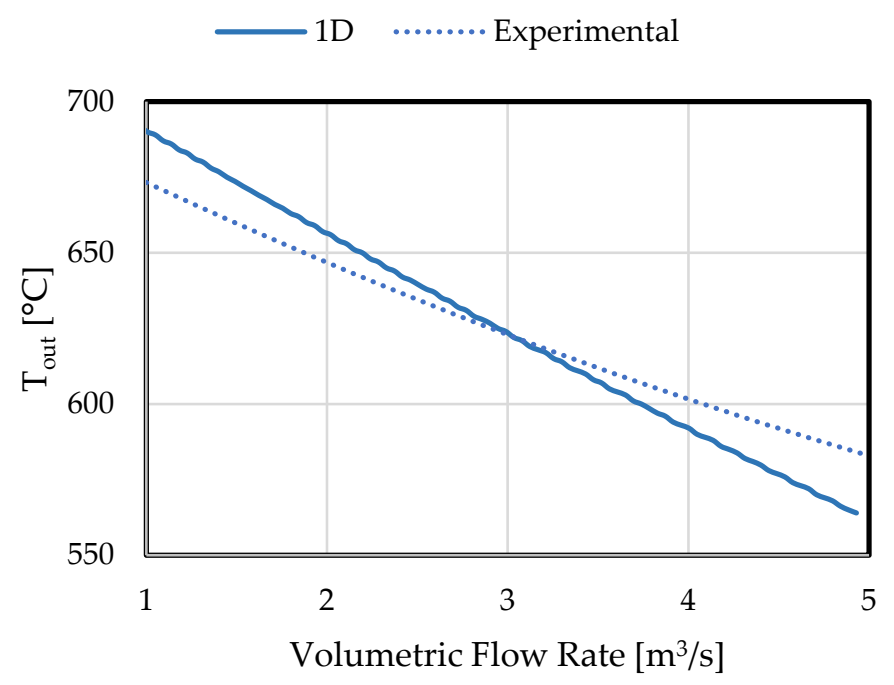

Figure 10. Results from receiver validation.

\subsubsection{Turbine Off-Design Model Validation}

The turbine model was validated against experimental data available in literature for a similar design [26] in terms of size and expansion ratio. Table 1 presents the main geometrical parameters of the turbine adopted for validation.

Table 1. Turbine geometrical specifications.

\begin{tabular}{cc}
\hline Rotor Inlet Tip Diameter & $99.1 \mathrm{~mm}$ \\
Rotor inlet tip width & $10.2 \mathrm{~mm}$ \\
Rotor inlet axial clearance, back-plate side & $0.25 \mathrm{~mm}$ \\
Rotor inlet axial clearance, shroud side & $0.4 \mathrm{~mm}$ \\
Rotor inlet blade angle & $0^{\circ}$ \\
Rotor blade number & 11 \\
Rotor exducer tip diameter & $79.0 \mathrm{~mm}$ \\
Rotor exducer hub diameter & $30.0 \mathrm{~mm}$ \\
Rotor exducer blade angle & $50.1^{\circ}$ \\
Rotor exducer blade thickness & $1.6 \mathrm{~mm}$ \\
Rotor exit radial clearance & $0.4 \mathrm{~mm}$ \\
\hline
\end{tabular}

Results of turbine model validation demonstrate good accuracy for a wide range of operational conditions, which also covers the actual operating condition of turbines of interest for this study (Figure 11). The model reproduces satisfactorily the behavior of the turbine, especially near choking condition, while for a given rotational speed, it seems to lose its accuracy towards lower mass flow rates. Nevertheless, the maximum relative error is low, apart from in a few working conditions where it reaches $13.1 \%$. Although the coefficient of determination, calculated using Equation (28), decreases with the rotational speed it stays above 0.994 . This ensures sufficient accuracy when predicting the corrected mass flow rate and the efficiency as functions of rotational speed and pressure ratio. Moreover, the inaccuracy of the model is associated within working points not representing typical working conditions and may not affect the accuracy of the cycle simulation.

$$
R^{2}=1-\frac{\sum\left(y_{i}-\hat{y}_{i}\right)^{2}}{\sum\left(y_{i}-\overline{y_{i}}\right)^{2}}
$$

In Equation (28), $y_{i}$ is the predicted value, $\hat{y}_{i}$ is the observed value and $\overline{y_{i}}$ is the mean value of the observed data. 


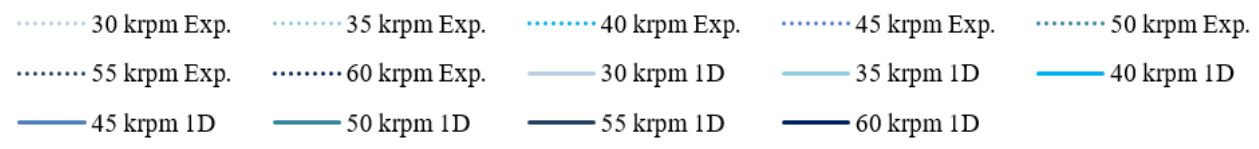

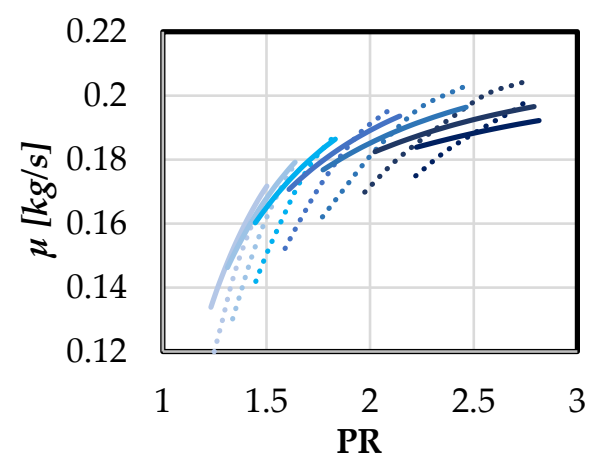

(a)

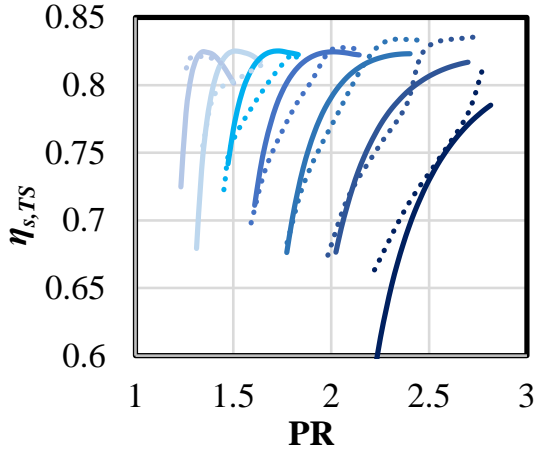

(b)

Figure 11. Results from turbine validation. (a) Corrected flow rate vs pressure ratio; (b) total to static isentropic efficiency vs pressure ratio.

\section{Results}

In this section a case study for a $7-\mathrm{kW}_{\mathrm{e}}$ MGT is discussed and the techno-economic performance of the plant is evaluated using the presented models. For verification of the components' matching a model developed in the commercial software IPSEpro, was used. The benchmark results for a pure-solar MGT-based CSP power plant are presented below. Finally, a plant-size optimisation has been performed to identify feasible economic solutions for a given set of conditions such as local solar irradiation pattern.

\subsection{Case Study}

In this section a case study considering a $7-\mathrm{kW}_{\mathrm{e}}$ pure-solar plant powered by microturbine is presented. The plant consists of a compressor, recuperator, solar receiver, turbine and a high-speed generator to convert the available mechanical energy to electricity. Preliminary design characteristics have been chosen based on the findings of the OMSoP project [6] and a previous study conducted by the authors [27]. Table 2 reports the preliminary design characteristics of the plant.

Table 2. Main design requirements.

\begin{tabular}{cc}
\hline \multicolumn{2}{c}{ Design Point Requirements } \\
\hline$\dot{m}[\mathrm{~kg} / \mathrm{s}]$ & 0.09 \\
DNI $\left[\mathrm{W} / \mathrm{m}^{2}\right]$ & 800 \\
$\boldsymbol{n}[\mathrm{krpm}]$ & 130 \\
$\boldsymbol{p}_{\mathbf{0 1}}[\mathrm{kPa}]$ & 101.3 \\
$\boldsymbol{T}_{\mathbf{0 1}}[\mathrm{K}]$ & 298 \\
TIT $[\mathrm{K}]$ & 1073 \\
\hline
\end{tabular}

The study has been performed considering data available in literature for solar irradiation in Rome for the period between 2004 and 2005. Figure 12 shows the DNI frequency diagram and the moving average of the DNI for a constant variation of $100 \mathrm{~W} / \mathrm{m}^{2}$ in the DNI. As can be seen in this figure, the highest average frequency levels are for the DNI are around the value of $800 \mathrm{~W} / \mathrm{m}^{2}$. For this reason, this value has been chosen as design DNI while DNIs lower than $300 \mathrm{~W} / \mathrm{m}^{2}$ have not been investigated due to negligible power that can be produced in such solar irradiation level. 


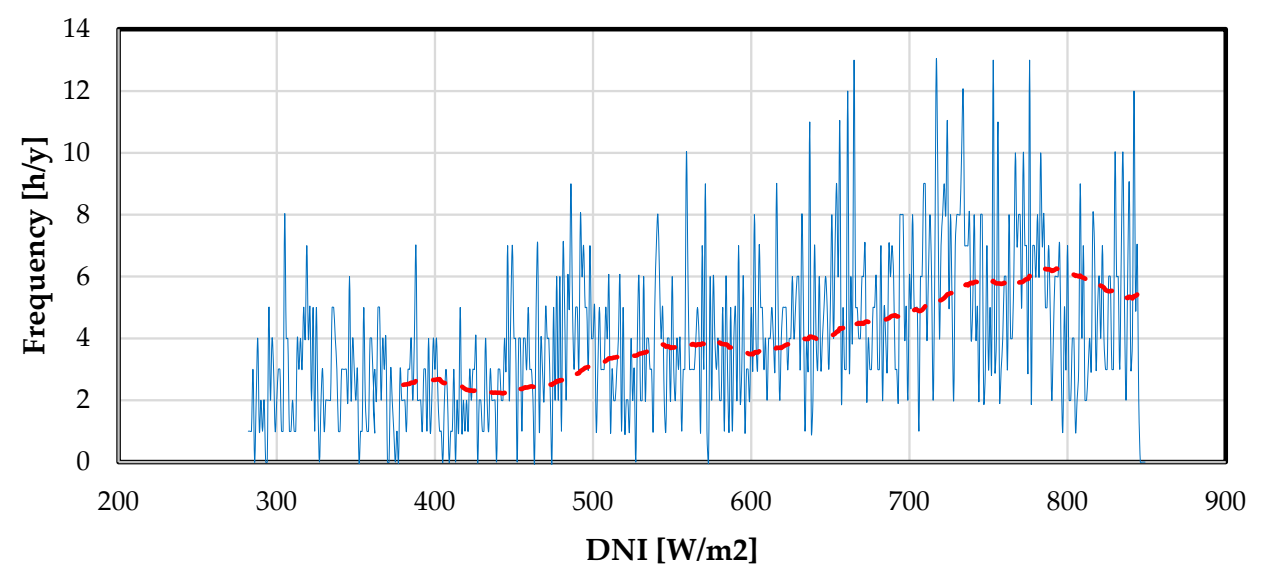

Figure 12. DNI frequencies in Rome for the period between 2004 and 2005 and the moving average of DNI (red line).

\subsection{Design Results}

The results from the design procedure are presented in Table 3 based on the design requirements presented in Table 2 and the chosen DNI. The net power output has been evaluated considering mechanical and electrical efficiencies of $85 \%$ and $90 \%$, respectively.

Using the models discussed previously, each component of the system was designed based on the performance parameters given in Table 3. The compressor is composed of an impeller with 12 blades and a vaneless diffuser of $60 \mathrm{~mm}$ radius. The impeller has a tip exit radius of $36 \mathrm{~mm}$ and width of $1.5 \mathrm{~mm}$; the isentropic efficiency of the compressor is 0.80 . The fin geometry $1 / 10-27.03$ has been adopted for the recuperator and it has an overall heat transfer area of about $17 \mathrm{~m}^{2}$ and a heat transfer to volume ratio of around $2900 \mathrm{~m}^{-1}$. Its effectiveness was set to 0.85 and the heat transfer coefficient was evaluated at $163 \mathrm{~W} / \mathrm{m}^{2} \mathrm{~K}$ and $119 \mathrm{~W} / \mathrm{m}^{2} \mathrm{~K}$ on the hot and cold sides, respectively. The pressure drop is estimated to be $1 \%$ on the hot side and $3 \%$ on the cold side. The receiver is characterised by a cavity diameter of $19 \mathrm{~cm}$ and length of $33.6 \mathrm{~cm}$. The overall length of the pipe, which has a diameter of $4 \mathrm{~cm}$, is $3.748 \mathrm{~m}$, and is formed of a helical coiled pipe with 8 turns. The efficiency of the receiver is 0.76 while the overall pressure loss is around $3 \%$. Based on the receiver performance, the dish aperture diameter required to produce the desired electrical power of $7 \mathrm{kWe}$ is $8.37 \mathrm{~m}$, assuming dish optical efficiency of 0.8 . The turbine impeller, with isentropic efficiency of 0.799 , consists of 11 blades with an inlet radius of $38.5 \mathrm{~mm}$, exit hub radius of $14.9 \mathrm{~mm}$ and exit tip radius of $28.6 \mathrm{~mm}$. Appendix A summarises the design parameters of the plant components.

Table 3. The design parameters for the 7-kWe plant.

\begin{tabular}{cccc}
\hline \multicolumn{2}{c}{ Thermodynamic Quantities } & \multicolumn{2}{c}{ Performance Parameters } \\
\hline$\dot{m}[\mathrm{~kg} / \mathrm{s}]$ & 0.09 & $\mathrm{P}_{\mathrm{c}}[\mathrm{W}]$ & $12,316.7$ \\
$\mathrm{DNI}\left[\mathrm{W} / \mathrm{m}^{2}\right]$ & 800 & $\mathrm{P}_{\mathrm{t}}[\mathrm{W}]$ & $20,361.7$ \\
$\mathrm{n}[\mathrm{krpm}]$ & 130 & $\mathrm{P}[\mathrm{W}]$ & 6878.4 \\
$p_{01}[\mathrm{kPa}]$ & 101.3 & $\eta_{c}$ & 0.796 \\
$p_{02}[\mathrm{kPa}]$ & 304.1 & $\varepsilon$ & 0.850 \\
$p_{03}[\mathrm{kPa}]$ & 305.5 & $\eta_{r}$ & 0.759 \\
$p_{04}[\mathrm{kPa}]$ & 299.5 & $\eta_{t}$ & 0.818 \\
$p_{05}[\mathrm{kPa}]$ & 103.9 & $\eta$ & 0.195 \\
$T_{01}[\mathrm{~K}]$ & 298.1 & - & - \\
$T_{02}[\mathrm{~K}]$ & 435.4 & - & - \\
$T_{03}[\mathrm{~K}]$ & 804.0 & - & - \\
$\mathrm{TIT}[\mathrm{K}]$ & 1074.6 & - & - \\
$T_{05}[\mathrm{~K}]$ & 869.2 & - & - \\
\hline
\end{tabular}

\subsection{IPSEpro Simulation Set-Up}

In addition to modelling the plant using the developed code, the microturbine was also modelled by IPSEpro, a commercial heat and mass balance software package for process and cycle analysis. 
The layout of the process units of the model is shown in Figure 1. Characteristics maps for the turbomachinery and recuperator have been generated based on the validated models of components as discussed in the preceding section and are implemented in the IPSEpro model for off-design calculations. Input parameters are rotational speed, DNI and ambient conditions, i.e., air relative humidity, ambient pressure and ambient temperature. The TIT is considered as constraint with maximum allowable limit of $1073 \pm 1 \mathrm{~K}$. When the limit of TIT is reached, the rotational speed, thus the air mass flow rate, and turbine outlet temperature are regulated to avoid exceeding the limit. The model outputs are pressure, temperature, mass flow rate and enthalpy downstream and upstream of the components, by which performance indicators such as power and electrical efficiency are calculated. The physical properties of gas components are calculated with polynomials derived from the JANAF (Joint Army Navy Air Force) Thermodynamic Tables [28]. In IPSEpro, all calculations were performed assuming that the gas components being ideal gases.

\subsection{Off-Design Results}

For a typical pure-solar application, the MGT operates at a constant TIT (at the highest allowable level) to maximise the overall efficiency of the plant. It should be noted that here, the TIT has been limited due to material limitation of the receiver rather than the turbine material. In case of OMSoP plant this limit was estimated to $1073 \mathrm{~K}$. To achieve a constant TIT, it is necessary to operate at variable mass flow rate and consequently variable rotational speed. For lower DNIs it would not be possible to achieve the highest allowable TIT, which means that the MGT will operate at lower efficiency. Moreover, the power output for these operating points is relatively low, as is their occurrence frequency as shown in Figure 13. As such, a minimum output power of the plant was fixed to $2000 \mathrm{~W}$ and points with lower power output were not considered. It should be emphasised that considering any power below this level would neither change the annual produced electricity significantly nor the levelised cost of electricity.

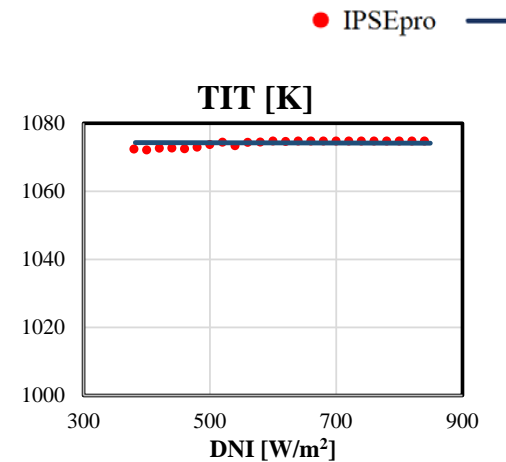

(a)

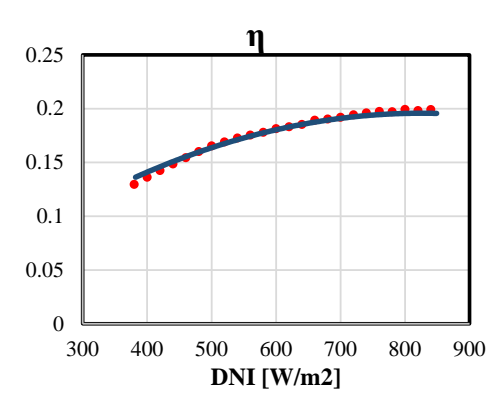

(c)

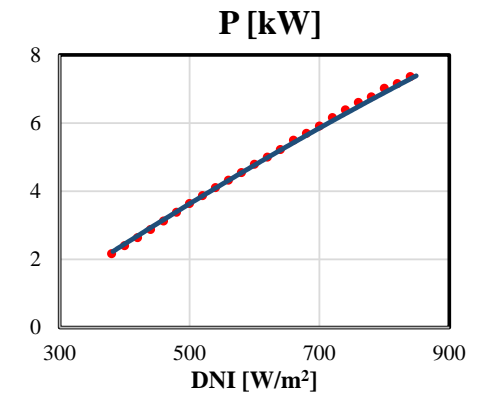

(b)

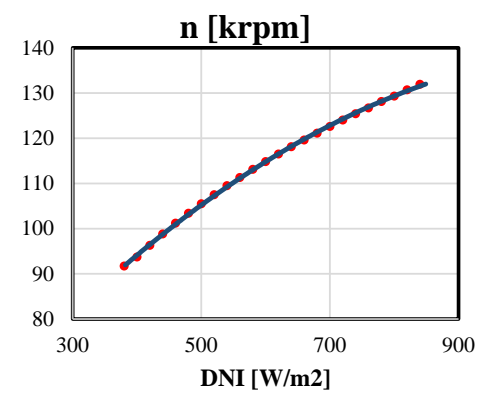

(d)

Figure 13. Plant off-design performance charts under variable DNI. (a) TIT; (b) output power; (c) efficiency; (d) rotational speed. 
The results of the present model have been compared with the results from IPSEpro where the same component characteristic maps and operational strategy were considered. This comparison was aimed to verify the component matching procedure adopted for the present model. The results in Figure 13 demonstrate good accuracy for the whole range of operation. The discrepancy in the results is due to the setup in IPSEpro where the TIT is limited not to a single value, $1073 \mathrm{~K}$ in this case, but to a range with a minimum tolerance of $1 \mathrm{~K}$. Thus, while the desirable TIT is set to $1073 \mathrm{~K}$ in the present model this parameter was set to $1073 \pm 1 \mathrm{~K}$ in the IPSEpro model.

\subsection{Cost Analysis}

The annual electricity generation and the levelised cost of electricity have been calculated using the components' characteristic maps and the plant overall performance parameters. The analysis has been carried out considering the DNI frequencies in Figure 13 based on hourly average values of Rome in the period between 2004 and 2005. The overall energy produced by the plant is 10,682 $\mathrm{kWh}$.

Figures 14 and 15 shows the breakdown of the overall energy produced along the year by each DNI level and, not surprisingly, the electricity is mostly produced during the high sun irradiance period in the range between 650 and $850 \mathrm{~W} / \mathrm{m}^{2}$.

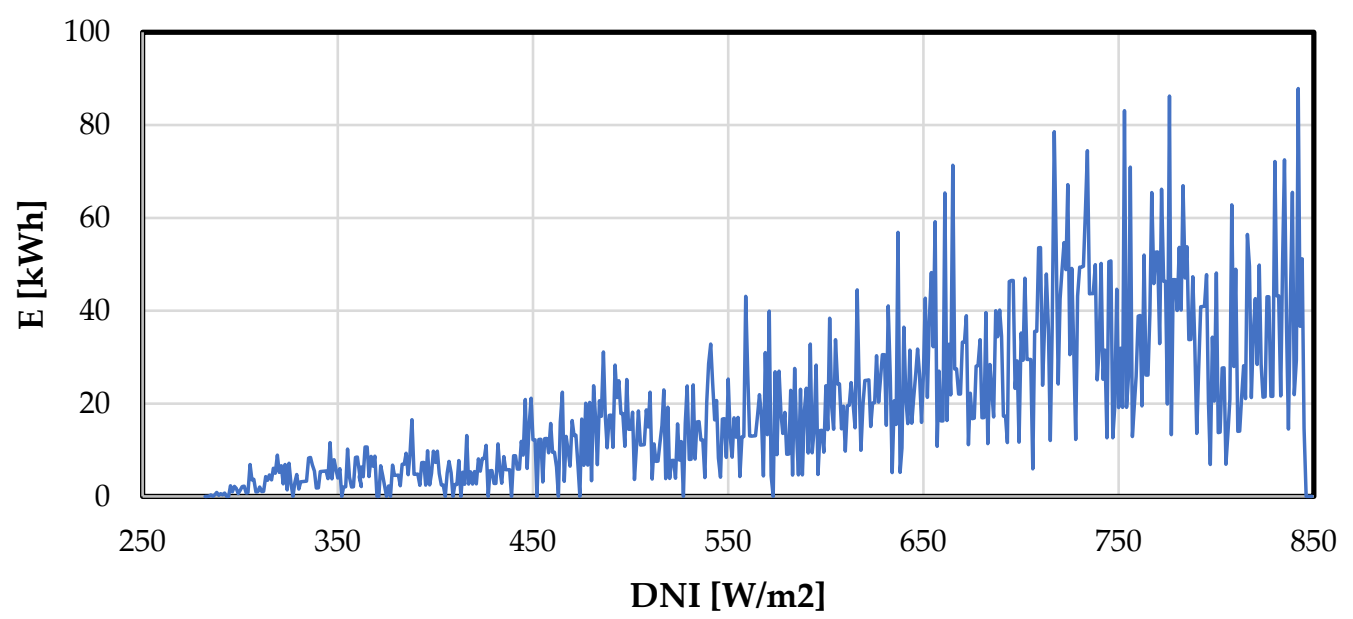

Figure 14. Annual energy produced at each DNI level.

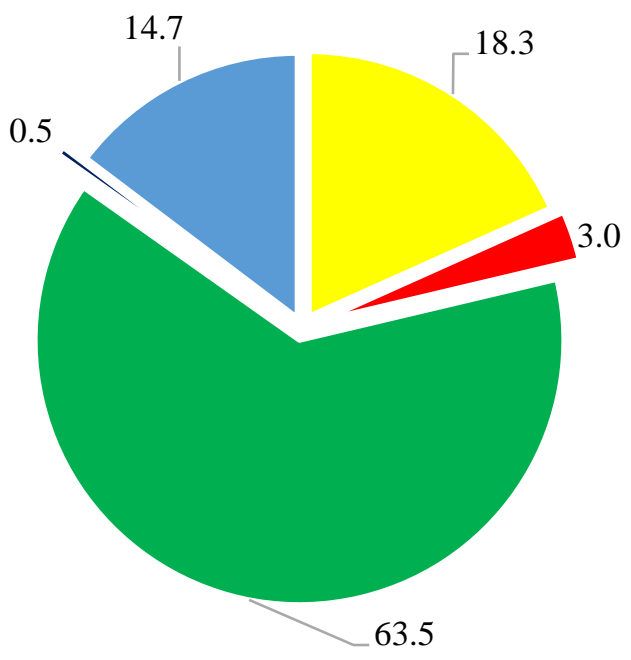

MGT

- Recever

- Dish

- Generator \& Power electronics

Installation

Figure 15. Cost breakdown of the plant.

The cost functions described previously have been used to estimate the cost of the plant and cost of producing electricity. Figure 15 shows the plant cost breakdown for different components of the 
plant. The capital cost has been estimated to be EUR 27,051 and, consequently, the specific cost of the plant, defined as the ratio between the cost of components and output power in design condition, has been estimated to be around EUR 3980/kWel. As can be seen in Figure 14, the most costly component is the dish, representing $63.5 \%$ of the overall cost, while the MGT represents $18.3 \%$ of the overall cost. Results from the LCOE analysis demonstrate a levelised cost of electricity of EUR $22.81 / \mathrm{kWh}$ considering a lifetime of the plant of 25 years.

\subsection{Plant Size Optimsation}

The analysis discussed above was repeated for different plant design parameters to optimise the plant size in order to achieve minimum LCOE while maximising the annual electrical production. Rome was selected as location site, characterised by DNI levels and frequencies already shown in Figure 12. For each given DNI an off-design performance analysis was carried out considering constant TIT as operational strategy. The overall energy produced during the year was then calculated together with the levelised cost of electricity. As discussed previously, the most costly component of the plant is the dish and its size is directly proportional to the mass flow rate for a given TIT. On the other hand, the mass flow rate is the main parameter influencing the power output of the plant and, subsequently, the annual electricity generation. For this reason, the mass flow rate was chosen as the optimisation variable, while pressure ratio and TIT were kept constant and equal to 3 and $1073 \mathrm{~K}$, respectively. The design space of the optimisation variable is limited to the values $0.07-0.16 \mathrm{~kg} / \mathrm{s}$. These limits have been evaluated to keep the compressor efficiency as high as possible by limiting the compressor specific speed to its optimum value. At both ends of this range, the compressor efficiency drops significantly.

Figure 16 shows the results of the optimisation. The performances of the plant considering dissimilar plant design mass flow rates have been compared in term of levelised cost of energy and annual energy produced. As shown in Figure 16a, results of the optimisation demonstrate a minimum LCOE of 21.5 [EUR $/ \mathrm{kWh}$ ] for a design point mass flow rate of about $0.11 \mathrm{~kg} / \mathrm{s}$. This corresponds to an overall cost of the plant around EUR 32,600, with a dish diameter of $9.4 \mathrm{~m}$ and an annual electricity production of $13,700[\mathrm{kWh}]$. As expected, the annual energy production increases with the mass flow rate as has been shown in Figure 16b. As shown in Figure 17, the range of DNIs, in which the plant produces more than $2 \mathrm{kWe}$, is getting wider with an increase of the mass flow rate. Nevertheless, the dish size and, consequently, the overall cost is proportional to the mass flow rate; the right trade-off between annual energy production and levelised cost of electricity should be decided based on particular power demand for each application. Figure 17 highlights that for the whole range of mass flow rates the majority of the annual energy produced still occurs in the range between 650 and $850\left[\mathrm{~W} / \mathrm{m}^{2} \mathrm{~K}\right]$.

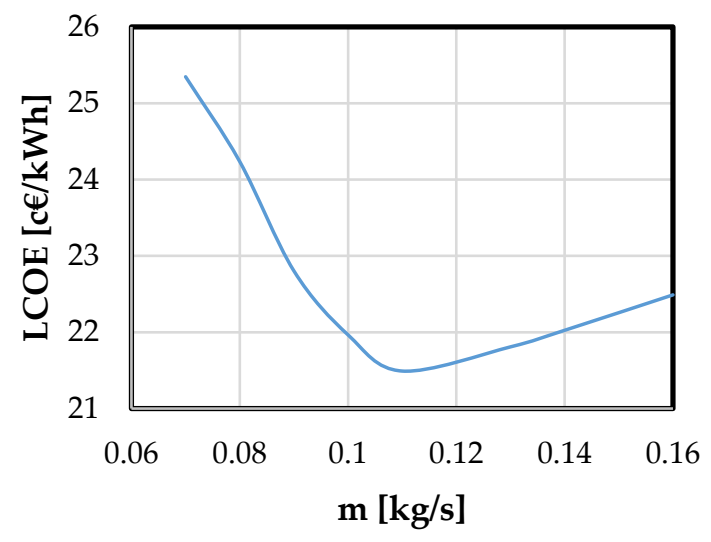

(a)

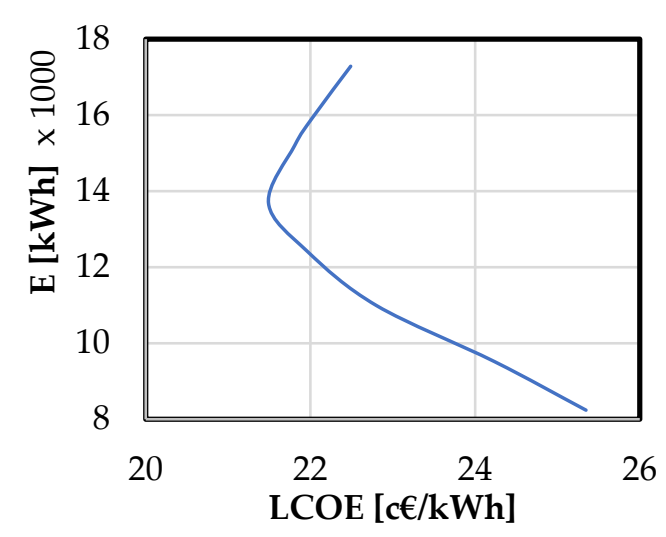

(b)

Figure 16. Plant size optimisation results. (a) Levelised cost of electricity (LCOE) as a function of the mass flow rate in design condition; (b) energy produced during the year as function of the LCOE. 


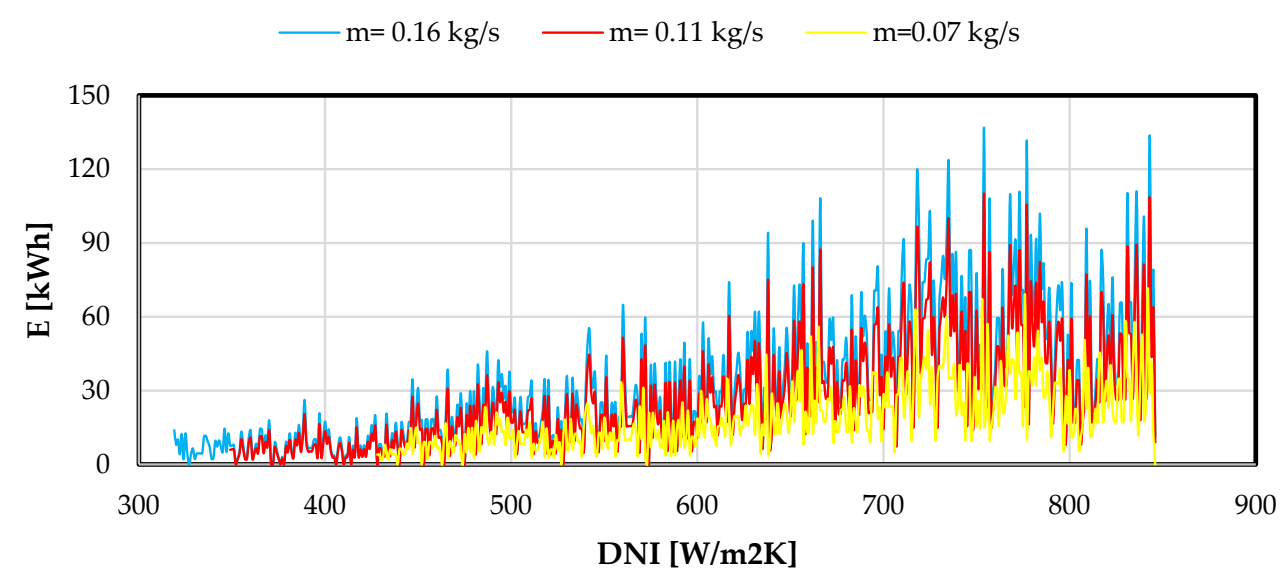

Figure 17. Specific annual power output for each DNI considering three different design mass flow rates.

\section{Discussions and Conclusions}

In this paper a techno-economic model for design optimisation and off-design performance evaluation of a pure-solar MGT-based plant was presented. The model adopted a modular approach using object-orientated programming where, for each component of the plant, a model was developed and validated against experimental data available in the literature. Results of the validation demonstrate good accuracy of the proposed models in a wide range of operating conditions.

A commercial software program, IPSEpro 7, for power cycle and process analysis, was used to verify the component matching procedure and cycle calculations for off-design conditions. The performance of a 7-kWe solar dish microturbine power plant was then analysed with the present platform and in the IPSEpro 7 environment. The components characteristic maps were generated based on one-dimensional modelling of the components and integrated into the models. These maps were also integrated in commercial software in order to validate the component matching routine. Results of the validation demonstrate good accuracy of the model in any working condition of the plant. From an economic point of view, the plant presents levelised cost of electricity of EUR 22.06/ $\mathrm{kWh}$, a capital cost of EUR 27,051 and a specific cost of the plant of about EUR $3980 / \mathrm{kW}_{\mathrm{e}}$. These results are comparable with those obtained by Gavagnin [7] considering $0.1 \mathrm{~kg} / \mathrm{s}$ as design mass flow rate and $500 \mathrm{unit} /$ year production rate. The author estimates a specific cost of the plant to be around EUR 3700/kWel. The cost breakdown also demonstrates comparable results. Gavagnin [7], based on real component costs provided by the OMSoP project supplier, estimates MGT representing $17 \%$ of the overall cost, the dish representing $62 \%$ and a receiver representing $4 \%$. The present study estimates the most costly component as the dish with $63.5 \%$ of the overall cost while the MGT represents $18.3 \%$ of the overall cost and the receiver $3 \%$. This demonstrates the applicability of the cost functions adopted in this study to estimate the overall cost of the plant. Nevertheless, comparison with previous studies [6,7], highlights the necessity of including the production rate as a further variable in the cost analysis.

A plant-size optimisation was then carried out to identify the plant size which minimises levelised cost of electricity while keeping the annual energy production as high as possible. Results of the optimisation demonstrates a minimum LCOE of 21.5 [EUR/ $\mathrm{kWh}$ ] for a design point mass flow rate of about $0.11 \mathrm{~kg} / \mathrm{s}$. This corresponds to an overall plant cost of EUR 32,600, with a dish diameter of $9.4 \mathrm{~m}$ and an annual electricity generation of $13,700[\mathrm{kWh}]$. Results from optimisation are comparable with those obtained by Ghavami [6]. The author performed an optimisation considering dissimilar plant size and sets of turbine inlet temperatures and recuperator effectiveness. The study highlights minimum levelised cost of energy around EUR $17 / \mathrm{kWh}$, when the TIT is increased to $950{ }^{\circ} \mathrm{C}$ and the recuperator effectiveness is improved up to $90 \%$. A parametric analysis considering dissimilar TIT and recuperator effectiveness, with due regard for components' material limitation and cost, will be considered in future studies. 
Future studies are also aimed to investigate the possibility to include two new modules in the software, such as combustion chamber and thermal energy storage unit. Integrated hybridization and/or thermal storage improves the dispatchability of the plant with consequent benefit for annual power output. Nevertheless, the right trade-off between component costs must be found. Furthermore, the software can be easily adopted to generate a database, which can be used to train machine learning algorithm. These algorithms can be easily integrated with a genetic algorithm for multi-objective optimisation purposes.

Supplementary Materials: Component's validation, already described in Section 2.3, are available online at http:/ /www.mdpi.com/1996-1073/11/11/3199/s1.

Author Contributions: Conceptualization, D.I., A.I.S., M.A. and J.A.Z.; Methodology, D.I.; Software, D.I. and H.N.; Validation, D.I. and H.N.; Formal Analysis, D.I.; Investigation, D.I.; Resources, A.I.S. and M.H.; Data Curation, D.I., H.N and J.A.Z.; Writing-Original Draft Preparation, D.I. and H.N.; Writing-Review \& Editing, A.I.S., M.H, and J.A.Z.; Visualization, D.I.; Supervision, A.I.S.; Project Administration, A.I.S.; Funding Acquisition, A.I.S.

Funding: This research received no external funding.

Conflicts of Interest: The authors declare no conflict of interest.

\section{Abbreviations}

$\begin{array}{ll}\text { CEPCI } & \text { Chemical Engineering Plant Cost Index } \\ \text { CSP } & \text { Concentrated Solar Power } \\ \text { DNI } & \text { Direct Normal Irradiation } \\ \text { MGT } & \text { Micro Gas Turbine } \\ \text { NTU } & \text { Number of transfer units } \\ \text { LCOE } & \text { Levelised cost of electricity }\end{array}$

\section{Nomenclature}

$\begin{array}{ll}A & \text { Recuperator heat transfer area }\left[\mathrm{m}^{2}\right] \\ b & \text { Width }[\mathrm{m}] \\ C & \text { Cost }[€] ; \text { Absolute Velocity }[\mathrm{m} / \mathrm{s}] \\ C_{p} & \text { Specific heat (constant pressure) }[\mathrm{kJ} / \mathrm{kg} \mathrm{K}] \\ E & \text { Annual net produced energy }[\mathrm{kWh}] \\ f & \text { Friction factor } \\ f_{m} & \text { material cost coefficient } \\ G & \text { Volumetric flow rate }\left[\mathrm{m}^{3} / \mathrm{s}\right] \\ h & \text { Heat transfer coefficient }\left[\mathrm{W} / \mathrm{m}^{2} \mathrm{~K}\right] ; \text { enthalpy }[\mathrm{J} / \mathrm{kg}] \\ J & \text { Colburn Number } \\ k & \text { Thermal Conductivity }[\mathrm{W} / \mathrm{m} \mathrm{K}] \\ L & \text { Recuperator Length and height } \\ L_{1} & \text { Recuperator depth } \\ m & \text { Mass Flow Rate }[\mathrm{kg} / \mathrm{s}] \\ N u & \text { Nusselt number } \\ P_{f} & \text { Recuperator fin length }[\mathrm{mm}] \\ p & \text { pressure }[\mathrm{kPa}] \\ P & \text { Power }[\mathrm{kW}] \\ P r & \text { Prandtl Number } \\ P R & \text { Pressure ratio } \\ R & \text { Radius }[\mathrm{m}] \\ R e & \text { Reynolds Number } \\ T & \text { Temperature }[\mathrm{K}] \\ U & \text { Overall heat transfer coefficient }\left[\mathrm{W} / \mathrm{m}^{2} \mathrm{~K}\right] \\ V & \text { Volume }\left[\mathrm{m}^{3}\right] \\ Z & \text { Number of impeller blades } \\ & \end{array}$




\title{
Greek Symbols
}

$\delta$

$\delta_{w}$

$\varepsilon$

$\eta$

$\eta_{o}$

$\theta$

$\lambda$

$\mu$

$\rho$

$\sigma_{b}$

\section{Suffix}

Recuperator fin thickness [m]

Recuperator plate thickness [m]

Recuperator effectiveness

efficiency

Fin efficiency

Receiver Inclination angle [rad]

Thermal Conductivity [W/mK]

Viscosity $\left[\mathrm{kg} \mathrm{m}^{2} / \mathrm{s}^{2}\right]$; Corrected flow rate

$\left[\mathrm{kgK}^{0.5} /\right.$ Pas]

Density $\left[\mathrm{kg} / \mathrm{m}^{3}\right]$

Boltzman constant $=1.38 \times 10^{-23}[\mathrm{~J} / \mathrm{K}]$

\author{
Compressor station 1; Turbine station 1 \\ Compressor station 2; Turbine station 2 \\ Compressor station 3; Turbine station 3 \\ Compressor station 4; Turbine station 4 \\ Axial component \\ Ambient \\ Compressor. Recuperator cold side \\ Design condition \\ gas \\ Inlet \\ Off-Design \\ Outlet \\ Hub; Recuperator hot side \\ Polytrophic \\ Recuperator \\ Isentropic \\ Tip. Turbine \\ Total to Total \\ Total to Static \\ wall; Tangential component
}

\section{Appendix A}

Detailed results of the components design and off-design performance for the compressor, receiver, dish, recuperator and the turbine are reported in Table A1.

\section{Component Maps}

The characteristic maps of the components have been generated based on the models provided in the paper. Figure A1 shows the compressor maps which were obtained considering an inlet pressure of $101.3 \mathrm{kPa}$ and inlet temperature of $289 \mathrm{~K}$. Each rotational speed line is limited by the choking limit for high mass flow rates and minimum efficiency of 0.7 for low mass flow rates which was considered as the surge limit at any rotational speed. The charts report the efficiency and the corrected mass flow rate as a function of the compressor pressure ratio, where the corrected mass flow rate is defined by Equation (A1).

$$
\mu=\frac{m \sqrt{\frac{T_{0, i n}}{289}}}{\frac{p_{0, i n}}{101,325}}
$$


Table A1. Detailed results of the component designs for the compressor, receiver, dish, recuperator and the turbine.

\begin{tabular}{|c|c|c|c|c|c|c|c|}
\hline \multicolumn{4}{|c|}{ Compressor } & \multicolumn{4}{|c|}{ Receiver and Dish } \\
\hline \multicolumn{2}{|c|}{ Thermodynamic Quantities } & \multicolumn{2}{|c|}{ Geometry } & \multicolumn{2}{|c|}{ Thermodynamic Quantities } & \multicolumn{2}{|c|}{ Geometry } \\
\hline$T_{01}[\mathrm{~K}]$ & 298 & $\mathrm{R}_{1 \mathrm{t}}[\mathrm{m}]$ & 0.0199 & $T_{\text {out }}[\mathrm{K}]$ & 1073 & $\mathrm{D}_{\mathrm{cav}}[\mathrm{m}]$ & 0.19 \\
\hline$p_{01}[\mathrm{kPa}]$ & 101.3 & $\mathrm{R}_{1 \mathrm{~h}}[\mathrm{~m}]$ & 0.0092 & $T_{\text {in }}[\mathrm{K}]$ & 803.7 & $\mathrm{~L}_{\mathrm{rec}}[\mathrm{m}]$ & 0.336 \\
\hline$T_{02}[\mathrm{~K}]$ & 435.4 & $\mathrm{R}_{2}[\mathrm{~m}]$ & 0.0368 & $p_{\text {in }}$ [pa] & 308.6 & $\mathrm{~L}_{\text {pipe }}[\mathrm{m}]$ & 3.748 \\
\hline$p_{02}[\mathrm{kPa}]$ & 304.1 & $\mathrm{~b}_{2}[\mathrm{~m}]$ & 0.0015 & $p_{\text {out }}[\mathrm{pa}]$ & 302.6 & $\mathrm{D}_{\text {pipe }}[\mathrm{m}]$ & 0.04 \\
\hline$p_{03}[\mathrm{kPa}]$ & 309.4 & Z & 12 & - & - & $\mathrm{D}_{\text {dish }}[\mathrm{m}]$ & 8.37 \\
\hline- & - & $\mathrm{b}_{3}[\mathrm{~m}]$ & 0.0015 & - & - & $\mathrm{N}_{\text {Turns }}$ & 8 \\
\hline- & - & $\mathrm{R}_{3}[\mathrm{~m}]$ & 0.1000 & \multicolumn{4}{|c|}{ Performances } \\
\hline \multicolumn{4}{|c|}{ Performances } & $\eta$ & 0.761 & $\mathrm{Q}_{\mathrm{rad} 2}[\mathrm{~W}]$ & 4577.5 \\
\hline \multirow{2}{*}{$\eta_{s, T S}$} & \multirow{2}{*}{0.796} & \multirow{2}{*}{$\eta_{\mathrm{p}}$} & \multirow{2}{*}{0.834} & $\mathrm{Q}[\mathrm{W}]$ & 26780.3 & $\mathrm{Q}_{\mathrm{rad} 3}[\mathrm{~W}]$ & 1760.6 \\
\hline & & & & $\mathrm{Q}_{\mathrm{rad} 1}[\mathrm{~W}]$ & 2044.2 & $\mathrm{Q}_{\text {Cond }}[\mathrm{W}]$ & 58.6 \\
\hline \multicolumn{4}{|c|}{ Recuperator } & \multicolumn{4}{|c|}{ Turbine } \\
\hline \multicolumn{2}{|c|}{ Geometry } & \multicolumn{2}{|c|}{ Heat Transfer } & \multicolumn{2}{|c|}{ Thermodynamic Quantities } & \multicolumn{2}{|c|}{ Geometry } \\
\hline $\mathrm{L}_{1}[\mathrm{~m}]$ & 0.303 & $\mathrm{~h}_{\mathrm{h}}\left[\mathrm{W} / \mathrm{m}^{2} \mathrm{~K}\right]$ & 163.246 & $\mathrm{~T}_{0, \text { in }}[\mathrm{K}]$ & 1073.6 & $\mathrm{R}_{4 \mathrm{t}}[\mathrm{m}]$ & 0.0286 \\
\hline $\mathrm{L}_{2}=\mathrm{L}_{3}[\mathrm{~m}]$ & 0.200 & $\mathrm{~h}_{\mathrm{c}}\left[\mathrm{W} / \mathrm{m}^{2} \mathrm{~K}\right]$ & 119.172 & $P_{0, \text { in }}[\mathrm{kPa}]$ & 298.9 & $\mathrm{R}_{4 \mathrm{~h}}[\mathrm{~m}]$ & 0.0149 \\
\hline $\mathrm{p}_{\mathrm{f}}[\mathrm{m}]$ & 0.002 & $\mathrm{~J}_{\mathrm{h}}$ & 0.02806 & $\mathrm{p}_{0, \text { out }}[\mathrm{kPa}]$ & 105.4 & $\mathrm{R}_{4 \mathrm{t}}[\mathrm{m}]$ & 0.0286 \\
\hline$\delta[\mathrm{mm}]$ & 0.102 & $\mathrm{~J}_{\mathrm{c}}$ & 0.02240 & $\mathrm{~T}_{0, \text { out }}[\mathrm{K}]$ & 868.3 & $\mathrm{R}_{2}[\mathrm{~m}]$ & 0.0385 \\
\hline$\delta_{w}[\mathrm{~mm}]$ & 0.500 & $f_{h}$ & 0.14841 & - & - & $\mathrm{b}_{2}[\mathrm{~m}]$ & 0.0044 \\
\hline$\lambda[\mathrm{m}]$ & 0.003 & $\mathrm{f}_{\mathrm{c}}$ & 0.10625 & & & $\mathrm{Z}$ & 11 \\
\hline $\mathrm{b}_{\mathrm{c}}=\mathrm{b}_{\mathrm{h}}[\mathrm{m}]$ & 0.001 & effectiveness & 0.85 & & & & \\
\hline \multicolumn{4}{|c|}{ Thermodynamic quantities } & \multicolumn{4}{|c|}{ Performances } \\
\hline $\mathrm{G}_{\mathrm{h}}\left[\mathrm{m}^{3} / \mathrm{s}\right]$ & 5.227 & $\mathrm{G}_{\mathrm{c}}\left[\mathrm{m}^{3} / \mathrm{s}\right]$ & 5.149 & $\eta_{\mathrm{s}, \mathrm{TS}}$ & 0.799 & $\eta_{\mathrm{p}}$ & 0.790 \\
\hline$T_{\text {hin }}[\mathrm{K}]$ & 868.5 & $\mathrm{~T}_{\text {cin }}[\mathrm{K}]$ & 436.4 & & & & \\
\hline $\mathrm{T}_{\text {hout }}[\mathrm{K}]$ & 527.6 & $\mathrm{~T}_{\text {cout }}[\mathrm{K}]$ & 803.7 & & & & \\
\hline$p_{\text {hin }}[\mathrm{kPa}]$ & 105.4 & $p_{\text {cin }}[\mathrm{kPa}]$ & 101.3 & & & & \\
\hline$p_{\text {hout }}[\mathrm{kPa}]$ & 309.5 & $p_{\text {cout }}[\mathrm{kPa}]$ & 308.6 & & & & \\
\hline
\end{tabular}

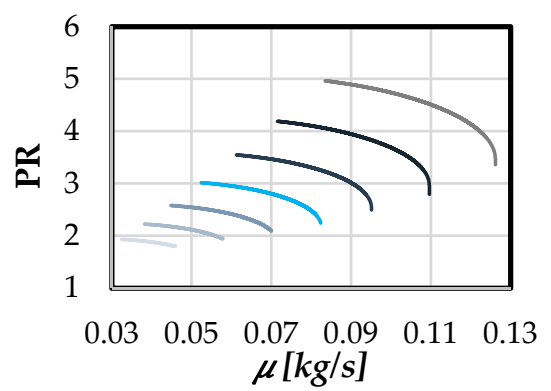

(a)

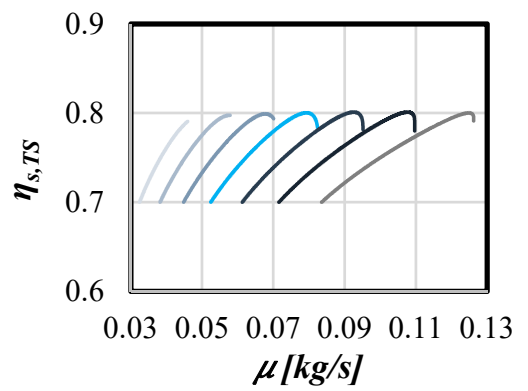

(b)

Figure A1. Compressor characteristic maps. (a) Pressure ratio vs corrected flow rate; (b) total to static isentropic efficiency vs corrected flow rate.

Figure A2 shows an example of the recuperator maps. The map has been calculated considering variable mass flow rate and constant inlet temperature for both fluids at the design point: $T_{\text {hot, in }}=869 \mathrm{~K}$ and $T_{\text {cold }, i n}=436 \mathrm{~K}$. Similar charts can be developed considering variable cold and hot inlet temperature. 
$\longrightarrow \Delta \mathrm{p}$ Hot Side

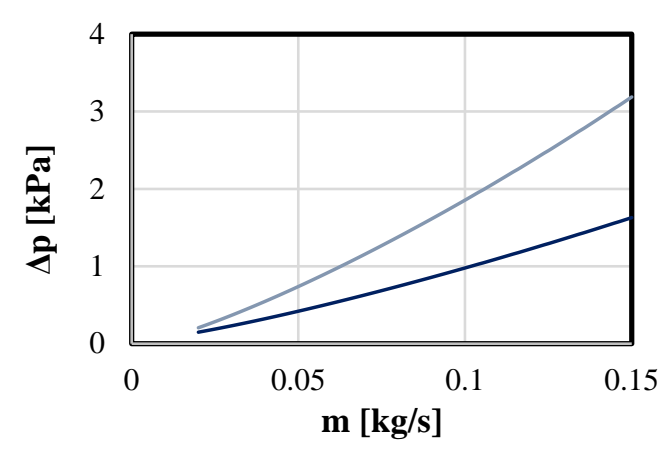

(a)

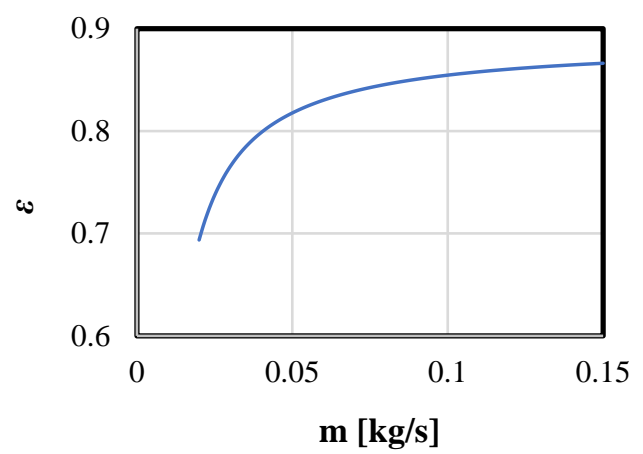

(b)

Figure A2. (a) Pressure drop across the recuperator as a function of the mass flow rate for both cold and hot side; (b) recuperator effectiveness as function of the mass flow rate.

The receiver maps have been generated by varying the DNI under variable mass flow rate at a given inlet temperature (Figure A3). The proposed one-dimensional model was used to calculate the outlet temperature, the receiver efficiency and the pressure drop. The results suggest that the efficiency of the receiver is directly proportional to the mass flow rate, but the DNI has the most influence on the efficiency and the maximum achievable efficiency is dictated by the DNI. The calculations have been performed for ambient temperature of $298 \mathrm{~K}$, inlet temperature of $800 \mathrm{~K}$ and inlet pressure of 308,600 Pa.

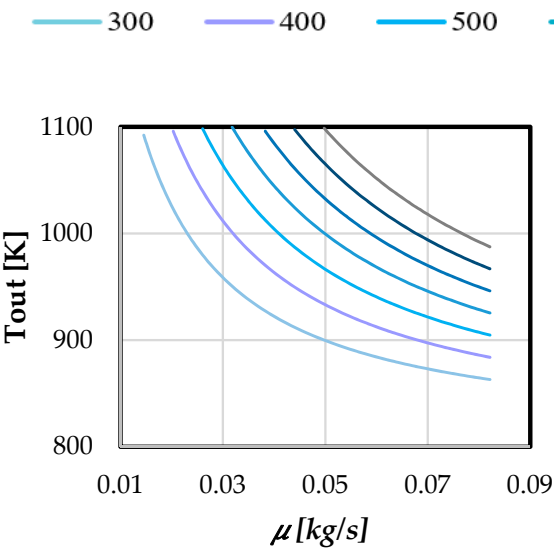

(a)

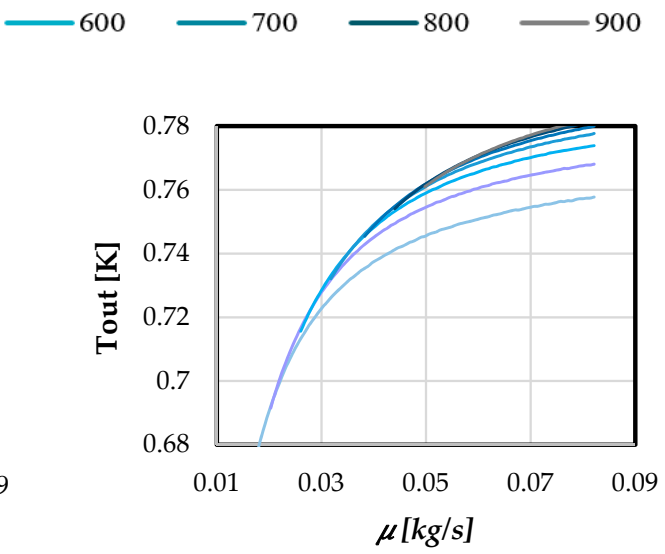

(b)

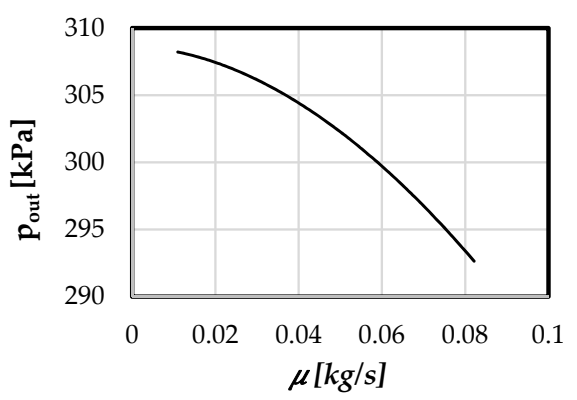

(c)

Figure A3. Receiver characteristic maps: variation of outlet temperature (a), efficiency (b) and pressure drop (c) with air corrected mass flow rate. 
Figure A4 shows the turbine maps obtained for different rotational speeds, in the same operating range of speed as the compressor and, similar to the compressor maps, each speed line is limited by the efficiency drop.

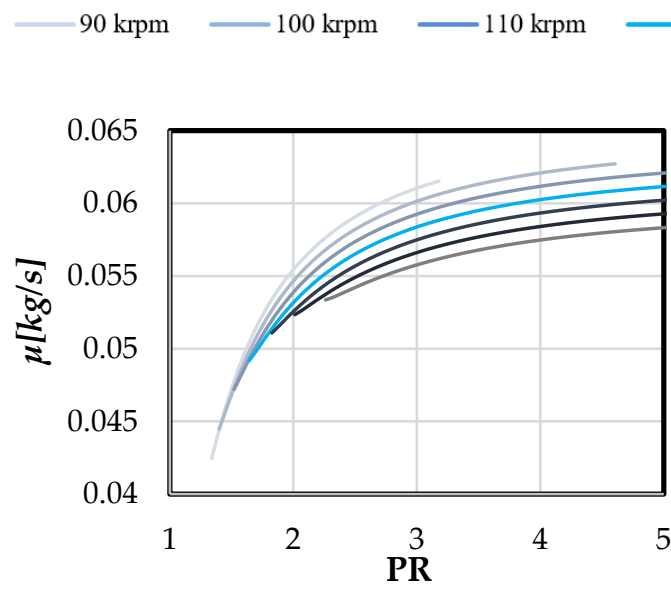

(a)

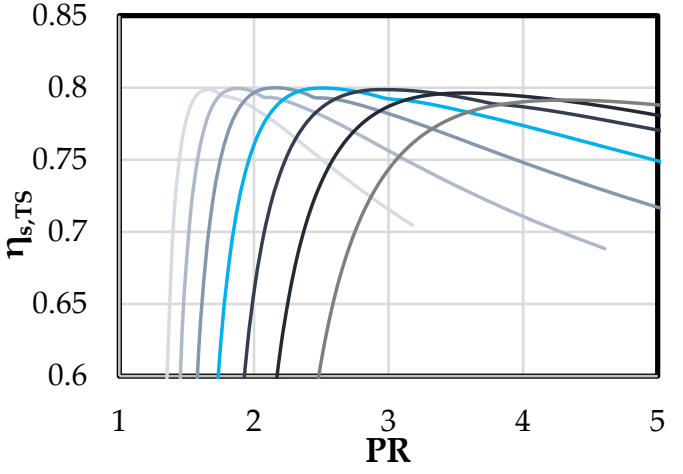

(b)

Figure A4. Turbine maps obtained for different rotational speeds. (a): corrected mass flow rate vs pressure ratio. (b): Total to static isentropic efficiency vs pressure ratio.

\section{References}

1. Lovegrove, K.; Stein, W. Concentrating Solar Power Technology; Woodhead Publishing: Cambridge, UK, 2012.

2. Aichmeyer, L.; Spelling, J.; Laumert, B.; Fransonn, T. Micro Gas Turbine Design for Small-Scale Hybrid Solar Power Plants. J. Eng. Gas Turbines Power 2013, 135, 113001. [CrossRef]

3. Qiu, K.; Yan, L.; Ni, M.; Wang, C.; Xiao, G.; Luo, Z.; Cen, K. Simulation and experimental study of an air tube-cavity solar receiver. Energy Convers. Manag. 2015, 103, 847-858. [CrossRef]

4. Lanchi, M.; Montecchi, M.; Crescenzi, T.; Mele, D.; Miliozzi, A.; Mazzei, D.; Misceo, M.; Falchetta, M.; Mancini, R. Investigation into the coupling of Micro Gas Turbines with CSP technology: OMSoP project. Energy Procedia 2015, 69, 1317-1326. [CrossRef]

5. Ragnolo, G.; Aichmayer, L.; Wang, W.; Strand, T.; Laumert, B. Technoeconomic design of a micro gas-turbine for a solar dish system. Energy Procedia 2015, 69, 1133-1142. [CrossRef]

6. Gavagnin, G.; Sánchez, D.; Rech, S.; Lazzaretto, A. Optimum design and performance of a solar dish microturbine using tailored component characteristics. Appl. Energy 2018, 231, 660-676. [CrossRef]

7. Mazzoni, S.; Cerri, G.; Chennaoui, L. A simulation tool for concentrated solar power based on micro gas turbine engines. Energy Convers. Manag. 2018, 174, 844-854. [CrossRef]

8. Cerri, G. A simultaneous solution method based on modular approach for power plant analyses and optimized designs and operations. In Proceedings of the ASME 1997 International Gas Turbine and Aeroengine Congress and Exhibition, Orlando, FL, USA, 2-5 June 1996; pp. 1-13.

9. Ghavami, M. Cycle Analysis and Optimisation of Micro Gas Turbines for Concentrated Solar Power. Ph.D. Thesis, University of London, London, UK, 2017.

10. Semprini, S.; Sanchez, D.; de Pascale, A. Performance analysis of a micro gas turbine and solar dish integrated system under different solar-only and hybrid operating conditions. Sol. Energy 2016, 132, 279-293. [CrossRef]

11. Ho Sung, L. Thermal Design: Heat Sinks, Thermoelectrics, Heat Pipes, Compact Heat Exchangers, and Solar Cells; John Wiley \& Sons: Hoboken, NJ, USA, 2011.

12. Iaria, D.; Al Zaili, J.; Sayma, A. Multi-objective optimisation of a centrifugal compressor for a micro gas turbine operated by concentrated solar power. In Proceedings of the 1st Global Power and Propulsion Forum, Zurich, Switzerland, 16-18 January 2017.

13. Whitefield, A.; Baines, N.C. Design of Radial Turbomachines; John Wiley \& Sons: New York, NY, USA, 1990.

14. Manglik, R.M.; Bergles, A. Heat Transfer and Pressure Drop Correlation for Rectangular Offset Strip Fin Compact Heat Exchangers. Exp. Therm. Fluid Sci. 1995, 10, 171-180. [CrossRef] 
15. Mustapha, H.; Japikse, D.; Baines, N.C.; Zelesky, M. Axial and Radial Turbines; Concepts NREC: White River Junction, VT, USA, 2003.

16. Wang, W.; Cai, R.; Zhang, N. General Characteristics of Single Shaft Microturbine Set at Variable Speed Operation and its Optimization. Appl. Therm. Eng. 2004, 24, 1851-1863. [CrossRef]

17. Zou, C.; Zhang, Y.; Falcoz, Q.; Neveu, P.; Zhang, C.; Shu, W.; Huang, S. Design and Optimization of a High-Temperature Cavity Receiver for a Solar Energy Cascade Utilization System. Renew. Energy 2017, 103, 478-489. [CrossRef]

18. Xin, R.C.; Ebadian, M.A. The effects of Prandtl numbers on local and average convective heat transfer characteristics in helical pipes. J. Heat Transf. 1997, 119, 467-473. [CrossRef]

19. Galanti, L.; Massardo, A. Micro Gas Turbine Thermodynamic and Economic Analysis up to $500 \mathrm{kWe}$ size. Appl. Energy 2011, 88, 4795-4802. [CrossRef]

20. Pioneer Engineering and Manufacturing Company. Cost Analysis of an Air Brayton Receiver for a Solar Thermal Electric Power System in Selected Annual Production Volumes; Jet Propulsion Laboratory: Pasadena, CA, USA, 1981.

21. Gallup, D.R. A Solarized Brayton Engine based on turbocharger technology and the DLR receiver. In Proceedings of the Intersociety Energy Conversion Engineering Conference, Monterey, CA, Canada, 7-11 August 1994; pp. 1719-1729.

22. Aichmeyer, L.; Spelling, J.; Laumert, B. Preliminary design and analysis of a novel solar receiver for a micro gas-turbine based solar dish system. Sol. Energy 2015, 114, 378-396. [CrossRef]

23. Botha, B.W.; Moolman, A. Determining the Impact of the Different Losses on Centrifugal Compressor Design. RED J. 2005, 21, 23-31.

24. Kays, W.M.; London, A.L. Compact Heat Exchangers; Krieger Pub. Co.: Malabar, FL, USA, 1998; Erratum in 1998.

25. Gang, X.; Yan, L.; Ni MWang, C.; Luo ZChen, K. Experimental Study of an Air Tube-Cavity Solar Receiver. Energy Procedia 2014, 61, 496-499.

26. Harley, P.; Spence, S.; Filsinger, D.; Dietrich, M.; Early, J. Assessing 1D loss models for the off-design performance prediction of automotive turbocharger compressors. In Proceedings of the ASME Turbo Expo 2013: Turbine Technical Conference and Exposition, San Antonio, TX, USA, 3-7 June 2013.

27. Iaria, D.; Alzaili, J.; Sayma, A.I. Solar Dish Micro Gas Turbine Technology for Distributed Power Generation. In Sustainable Energy Technology and Policies; De, S., Bandyopadhyay, S., Assadi, M., Mukherjee, D., Eds.; Green Energy and Technology; Springer: Singapore, 2018.

28. Simtech. IPSEpro, version 4.0; Simtech Simulation Technology (Simtech): Graz, Austria, 2012. 